\title{
Antarctic 20th Century Accumulation Changes Based on Regional Climate Model Simulations
}

\author{
Klaus Dethloff, ${ }^{1}$ Ksenia Glushak, ${ }^{2}$ Annette Rinke, ${ }^{1}$ and Dörthe Handorf ${ }^{1}$ \\ ${ }^{1}$ Alfred Wegener Institute for Polar and Marine Research, Research Unit Potsdam, Telegrafenberg A43, 14473 Potsdam, Germany \\ ${ }^{2}$ Max Planck Institute for Meteorology, Model and Data, Bundestrasse 53, 20146 Hamburg, Germany \\ Correspondence should be addressed to Klaus Dethloff, klaus.dethloff@awi.de
}

Received 30 October 2009; Revised 3 March 2010; Accepted 6 April 2010

Academic Editor: Jürg Luterbacher

Copyright (C) 2010 Klaus Dethloff et al. This is an open access article distributed under the Creative Commons Attribution License, which permits unrestricted use, distribution, and reproduction in any medium, provided the original work is properly cited.

\begin{abstract}
The regional climate model HIRHAM has been applied to Antarctica driven at the lateral and lower boundaries by European Reanalysis data ERA-40 for the period 1958-1998. Simulations over 4 decades, carried out with a horizontal resolution of $50 \mathrm{~km}$, deliver a realistic simulation of the Antarctic atmospheric circulation, synoptic-scale pressure systems, and the spatial distribution of precipitation minus sublimation (P-E) structures. The simulated P-E pattern is in qualitative agreement with glaciological estimates. The estimated (P-E) trends demonstrate surfacemass accumulation increase at the West Antarctic coasts and reductions in parts of East Antarctica. The influence of the Antarctic Oscillation (AAO) on the near-surface climate and the surface mass accumulation over Antarctica have been investigated on the basis of ERA-40 data and HIRHAM simulations. It is shown that the regional accumulation changes are largely driven by changes in the transient activity around the Antarctic coasts due to the varying AAO phases. During positive AAO, more transient pressure systems travelling towards the continent, and Western Antarctica and parts of South-Eastern Antarctica gain more precipitation and mass. Over central Antarctica the prevailing anticyclone causes a strengthening of polar desertification connected with a reduced surface mass balance in the northern part of East Antarctica.
\end{abstract}

\section{Introduction}

Antarctica responds to regional and global climate forcing factors. Doran et al. [1] observed a rapid surface warming on the Antarctic Peninsula and evidence of cooling elsewhere on the continent by analyzing station data from 1966 to 2000. Controversially Steig et al. [2] reported a significant warming, which extends well beyond the Antarctic Peninsula and covers most of West Antarctica. Jacobs and Comiso [3] documented declining sea ice extent in the mid and late 20th century around the Antarctic as a whole and regionally in the Amundsen and Bellingshausen Seas.

Vaughan et al. [4] discussed the insufficient current knowledge of the mechanisms and spatial distribution of climate change and showed that only large-scale variations can be predicted with some degree of confidence. Connolley and O'Farrell [5] explained that with coarse resolution and simplified physics, the current generation of Global Climate Models (GCMs) do not capture regional climate change with high skill. Although GCMs constitute the primary tool for capturing the behaviour of Earth's climate system, Regional Climate Model (RCM) systems with higher spatial and temporal resolutions can add value at medium scales to the climate statistics when driven by GCMs with accurate large scales.

A major component of interannual to decadal variability in the Southern Hemisphere (SH) is the Antarctic Oscillation (AAO), described by Gong and Wang [6]. This oscillation refers to a large-scale alternation of atmospheric mass between the mid-latitude and high-latitude surface pressures and describes the principal mode of variability in the SH. It represents the strengthening and weakening of the belt of tropospheric westerlies surrounding Antarctica. The AAO shifted into a positive oscillation phase over recent decades as a result of stratospheric ozone depletion, greenhouse gas changes, and natural factors, including the variability in the tropical Pacific sea surface temperatures described by Gillett and Thompson [7] and Fogt and 
Bromwich [8]. The question arises, how these global scale changes are imprinting on regional climate changes over Antarctica. Marshall et al. [9] examined the relationship between the AAO and Antarctic near-surface temperatures using data from Antarctic stations for 1957-2004. These studies demonstrated that this correlation is positive over the Antarctic Peninsula and negative elsewhere over the continent. Changes in the meridional pressure gradient during the positive AAO have intensified the westerlies that encircle Antarctica and affect the North-Western Peninsula. Van de Berg et al. [10] analysed simulations with the RACMO model from 1958-2002 to assess the response of Antarctic near surface climate to AAO changes. Their modelled surface mass balance agreed well with earlier model simulations and observational estimates but overestimated the mass balance at the steep coastal slopes of Antarctica.

Because observations of precipitation are very limited in Antarctica, one way to understand the precipitation variability is through RCM simulations driven by reanalysis. RCMs have proven be particularly useful in regions of complex topography and for simulating precipitation processes providing accurate time-varying lateral boundaries of the model domain. The transfer of heat, moisture, and momentum across the boundaries plays a fundamental role in mesoscale circulations. Recent changes in the hydrological cycle with impacts on precipitation and accumulation patterns are influenced by substantial shifts in the AAO. With the AAO trending toward a more positive phase, atmospheric circulation changes also effect climate conditions over Antarctica. It is therefore of interest to analyze the trends in Antarctic precipitation and accumulation and to investigate how much of this can be attributed to the major climate variability mode of the $\mathrm{SH}$, the AAO. An attempt is made here to explain the trends in Antarctic precipitation and accumulation in relation to long-term changes in the AAO. Owing to the short and sparse record of high quality data in the $\mathrm{SH}$, simulations with a high resolution regional climate model, driven by reanalysis data, are analysed. Surface mass balance defined as "precipitation minus sublimation minus runoff" is the component of the total ice sheet mass balance that is most directly affected by atmospheric climate changes. Detailed studies of climate change in particular in regions of strong topographical contrasts such as ice sheet margins, require high-resolution information provided through RCM simulations or stretched-grid atmospheric general circulation model, examined by Krinner et al. [11].

One important advance for understanding atmospheric behaviour around and over Antarctica has come from reanalysis products, which allows to undertake atmospheric studies at the SH high-latitudes with a level of confidence not available before. Monaghan et al. [12] examined the variability and trends in Antarctic precipitation minus evaporation (P-E) from RCM fields and reanalysis from 1985 onward. The trends in the NCEP/NCAR reanalysis are positive, while the ERA-40 trends are negative. Their scatter clearly indicates that Antarctic precipitation variability is markedly different between the reanalysis. Monaghan et al.
[12] conclude that the precipitation trend from ERA-40 is the most realistic, as ERA-40 has the best agreement with available observations from 1985-2001 over the majority of the continent. The period for which ERA-40 precipitation might be considered most reliable is subsequent to the discontinuity that occurred in 1979. Trenberth et al. [13] detected spurious trends in both the mass of dry air and atmospheric moisture arising from changes in the observing system, especially prior to 1979 before reliable satellite data became available for global analyses. Spurious fluctuations in global mean surface pressure on the order of $0.6 \mathrm{hPa}$ occur and primarily arise from low quality analyses over the Southern Oceans with surface pressures generally higher around Antarctica. Jones and Lister [14] showed that different reanalysis differ most strongly over Antarctica.

In this paper we apply the regional climate model HIRHAM on a circum-Antarctic domain and analyse a 40year-long simulation 1958-1998 driven by ECMWF reanalysis (ERA-40 data). Regional Antarctic climate changes for the two 20-year-long time slices 1958-1978 and 1979-1998 and for positive and negative AAO phases have been studied focussing on changes in synoptic pressure systems and the surface mass accumulation (P-E). In Section 2 we describe the applied HIRHAM RCM and the driving lower and lateral boundary reanalysis data. In Section 3, we present results of the HIRHAM simulations and compare them with reanalysis data. Section 4 gives a summary.

\section{The RCM Set-Up}

The RCM employed in this study is the HIRHAM model described for an Arctic application area by Dethloff et al. [15] and Rinke et al. [16]. It is a primitive equation hydrostatic model of the atmosphere configured at a $55 \mathrm{~km}$ horizontal resolution and 25 vertical levels in a hybrid sigma-pressure coordinate system with the lowest level at $12 \mathrm{~m}, 10$ level in the lowest $1 \mathrm{~km}$, and the top at $10 \mathrm{hPa}$. The model has been adapted to the extreme Antarctic conditions by introducing five additional vertical model layers in the lowest $1000 \mathrm{~m}$ within the atmospheric planetary boundary layer to better resolve near surface inversions, katabatic wind and the lowlevel wind jet. The lowest model layer was introduced at $12 \mathrm{~m}$ above the surface to capture the strong temperature and wind gradients near the surface. A detailed comparison of these HIRHAM simulations with station data is presented by Xin et al. [17] for the three East Antarctic stations Davis, Mawson and Casey.

HIRHAM is forced at its boundaries by ECMWF reanalysis ERA-40 at T 106 truncation, corresponding to a horizontal resolution of approximately $125 \mathrm{~km},[18]$. Marshall [19] demonstrated that ERA-40 is currently the reanalysis that best represents mean sea level pressure (MSLP) at SH high-latitudes, although significant biases may occur prior to the assimilation of satellite sounder data. The model is forced at the lateral boundaries by temperature, horizontal wind, specific humidity and surface pressure, updated every 6 hours. No nudging method, like, for example, spectral 


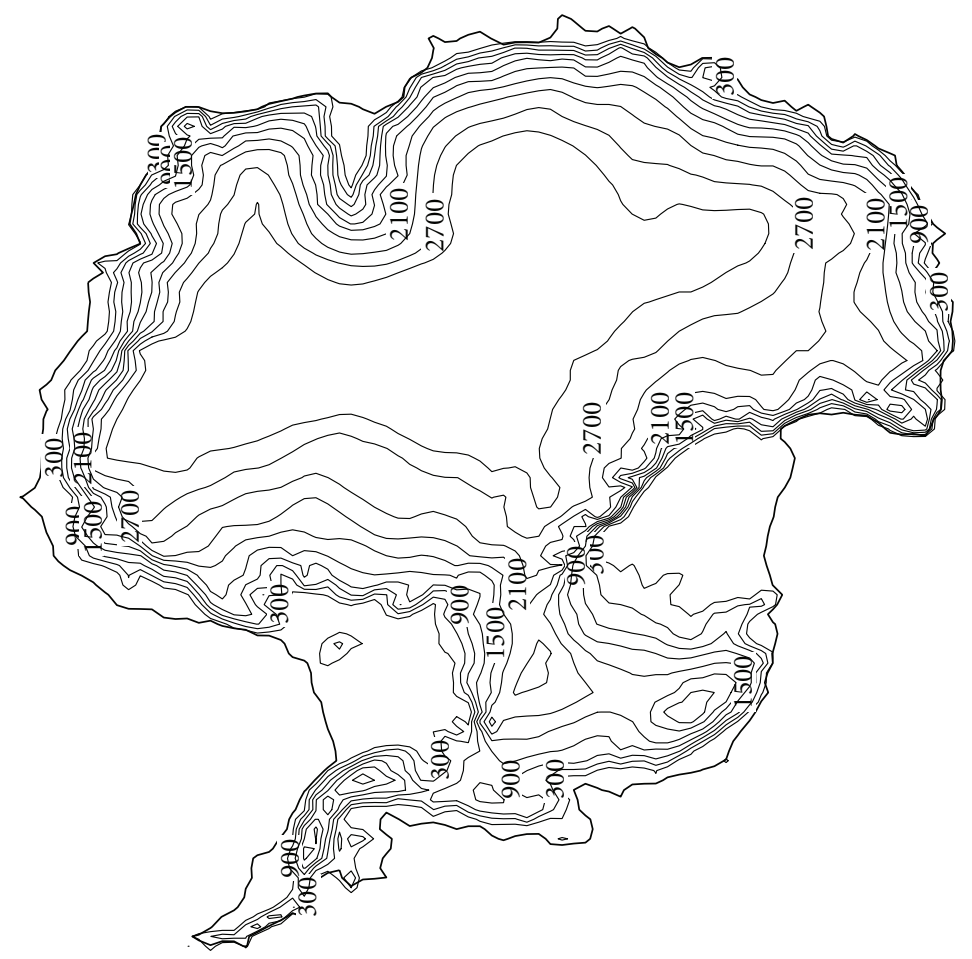

FIGURE 1: HIRHAM model domain with topography. Elevation contours (m).

nudging as suggested by Von Storch et al. [20] has been applied. At the ocean lower boundary, the model is forced by sea surface temperatures (SSTs), daily updatedcsea ice fraction, and a constant sea ice thickness of $2 \mathrm{~m}$. The sea ice and ice sheet surface temperatures are calculated prognostically via a heat balance equation linearised in both temperature and time. The model domain used in this study consist of $122 \times 110$ grid points, centered at the South Pole with a horizontal polar stereographic projection of $55 \mathrm{~km}$. Figure 1 shows the topography in the model domain with elevation contours $(\mathrm{m})$.

HIRHAM contains the physical parameterization package of the general circulation model ECHAM4 [21] which includes radiation, cumulus convection, planetary boundary layer and land surface processes, and gravity wave drag. The land surface scheme considers the heat and water budgets in the soil, snow cover and land and the heat budget of permanent land and sea ice. The albedo of snow and ice surfaces is a function of surface temperature. A diagnostic cloud scheme is used and sub-grid-scale condensation and cloud formation is taken into account by specifying appropriate thresholds for relative humidity depending on altitude and static stability. The cloud cover fraction at each model level is parameterised as a nonlinear function of the grid cell mean relative humidity at this level. The total cloud cover in a vertical column represents a type of maximum random overlap. With this approach, vertically continuous clouds are assumed to be overlapped to their maximum possibility, while clouds at different heights, that are separated by an entirely cloud-free model level, are randomly overlapped. A time step of 120 seconds is used.
The accuracy of RCM simulations is limited by the initial and lateral boundary conditions obtained from the reanalysis, the domain size, the resolution and the physical parameterization schemes. The lateral boundaries are placed far enough from the Antarctic coasts to reduce the impact of the lateral boundaries as discussed by Rinke and Dethloff [22] and $\mathrm{Wu}$ et al. [23]. The HIRHAM model has been applied on a circum-Antarctic domain and a long term climate model simulation from 1958-1998 was carried out. The model was validated against ERA-40 reanalysis data and selected station data and it appeared that the climatological mean patterns of $2 \mathrm{~m}$ air temperature, mean sea level pressure, and $500 \mathrm{hPa}$ geopotential and their interannual variability can be reproduced by the model (not shown). This is in agreement with Bromwich et al. [24], who conclude that RCMs tend to show smaller temperature and precipitation biases in Antarctica compared to global circulation models if driven by boundary conditions from data reanalysis.

\section{RCM Simulation Results}

3.1. Spatial Patterns of Surface Wind and Trends of Accumulation. A main factor controlling the atmospheric circulation of Antarctica is the persistent near surface wind connected to surface inversions. Figure 2 displays the $12 \mathrm{~m}$ wind vectors, interpolated for ERA-40 during Southern Hemisphere winter (JJA) and summer (DJF) conditions averaged over the simulation period $1958-1998$ by ERA-40 and HIRHAM. The different topography resolution of ERA-40 and HIRHAM affects the wind vectors. During summer and winter the 

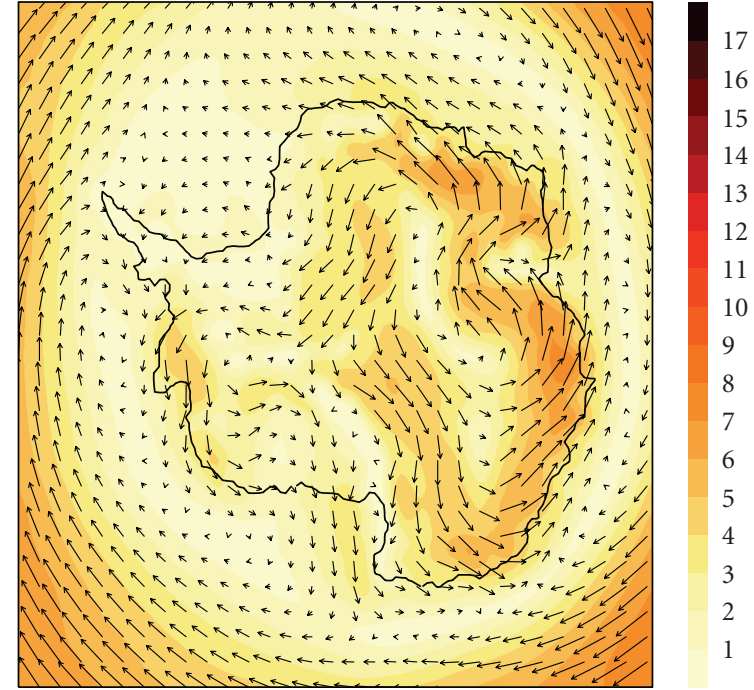

9

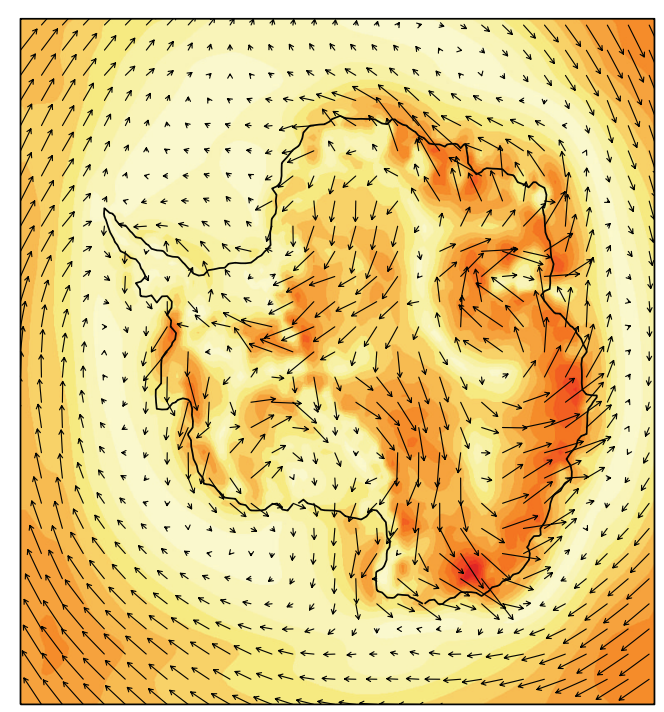

$\overrightarrow{10}$

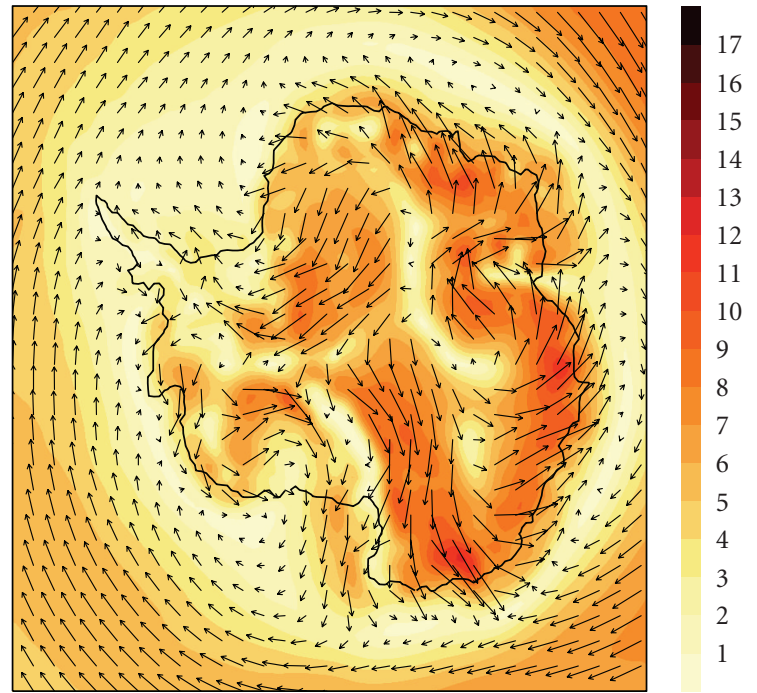

$\overrightarrow{10}$

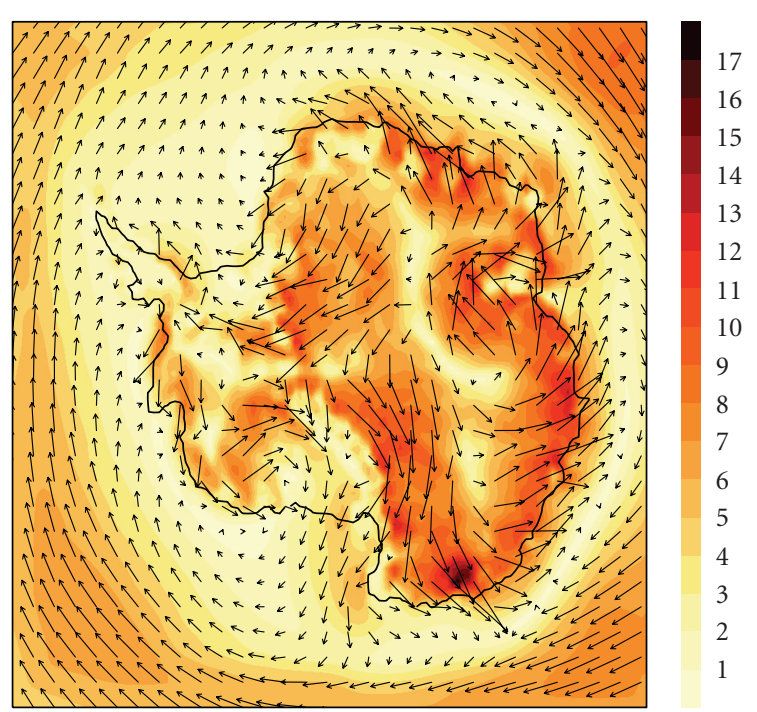

$\overrightarrow{10}$

(a)

(b)

FIgURE 2: (a) Wind speed contours (m/s) and wind direction (arrows) at the lowest HIRHAM level at $12 \mathrm{~m}$ during Southern Hemisphere summer (DJF) for the period 1958-1998. ERA-40 (top) and HIRHAM (bottom). (b) Wind speed contours (m/s) and wind direction (arrows) at the lowest HIRHAM level at $12 \mathrm{~m}$ during Southern Hemisphere winter (JJA) for the period 1958-1998. ERA-40 (top) and HIRHAM (bottom).

mean wind vectors and wind speed around the Antarctic coasts and over the continent from the HIRHAM simulations reproduce the ERA-40 reanalysis data. The HIRHAM mesoscale simulations clearly produce the continent scale drainage flow over East Antarctica. The flow is deflected to the left by the Coriolis force producing a net easterly component to the flow over Antarctica. HIRHAM simulates stronger wind fields over the coastal line and the near surface winds compared to ERA-40 are stronger during summer by $2 \mathrm{~m} / \mathrm{s}$ and by $4-6 \mathrm{~m} / \mathrm{s}$ during winter. Katabatic winds are most pronounced near the coast, where the ice sheet has its strongest slope. The major differences between HIRHAM and ERA-40 occur at the coastlines and valleys as a result of the different horizontal resolution. The stronger HIRHAM katabatic winds agree better with station data around the Antarctic coasts. The associated drift snow effects are important for the redistribution of the snowfall. During winter HIRHAM simulates lower wind speeds over the continent maintaining the strong surface inversions there, which is in agreement with the inner Antarctic station data at Amundsen-Scott and Vostock provided by British Antarctic Survey (BAS) (http://www.antarctica.ac.uk/met/READER). 


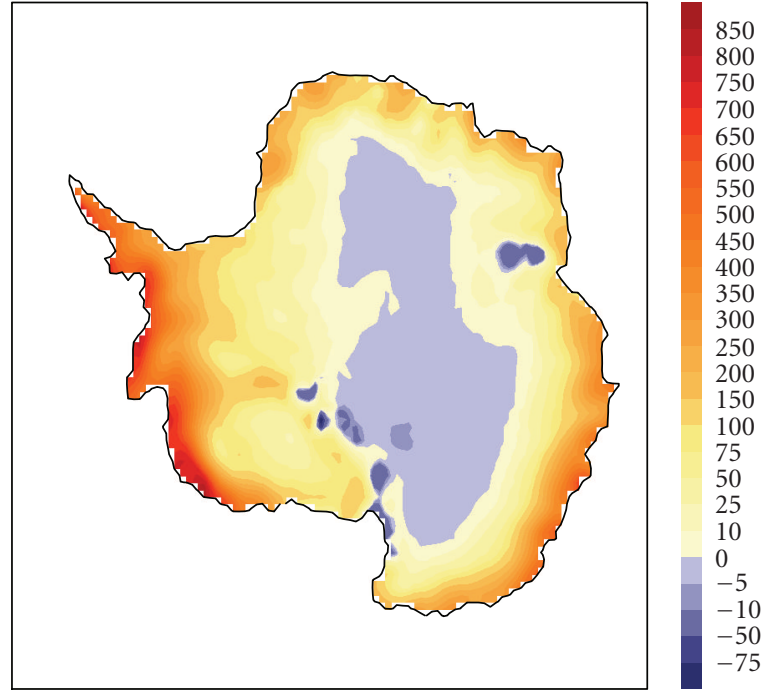

Figure 3: Annual net surface mass accumulation "precipitation minus sublimation (P-E)" ( $\mathrm{mm} /$ year) averaged over the time period 1958-1998 for ERA-40.

Because snow accumulation is critical in determining the evolution of the mass balance of the ice sheets, the precipitation amount is the most critical parameter for a accurate determination of accumulation. The accumulation term is the primary mass input to the Antarctic ice sheets, and is the net result of precipitation, sublimation/vapour deposition, drifting snow processes, melt and ice mass flux divergence. Precipitation is dominant among these components and establishing its spatial and temporal variability is necessary to assess ice sheet surface mass balance. The precipitation pattern is influenced to first order by the cyclonic activity around the Antarctic topography. Most of the precipitation fall along the steep coastal margins and is caused by orographic lifting of relatively warm, moist air associated with the transient, synoptic-scale cyclones that encircle the continent.

The most reliable source for identifying the spatial distribution of Antarctic precipitation (not shown) comes from the long-term annual accumulation depiction synthesized over the Antarctic ice sheets from glaciological data by Vaughan et al. [25], superseded by Arthern et al. [26]. Figure 3 displays the net mass accumulation described by the difference between "precipitation minus sublimation (P-E)" for ERA-40 and Figure 4 for HIRHAM over the whole simulation period 1958-1998. Obvious differences between the ERA-40 and the HIRHAM mass accumulation pattern occur not only in the inner Antarctica but also at the coastal regions of West and East Antarctica. The HIRHAM simulations are in qualitative agreement with the glaciological compilations of Antarctic mass balance, by Vaughan et al. [25] and Arthern et al. [26]. Compared to those accumulation analysis, all major features are well reproduced, with large values along the coast of East and West Antarctica, and over the Antarctic Peninsula and small amounts over the plateau of East Antarctica. The

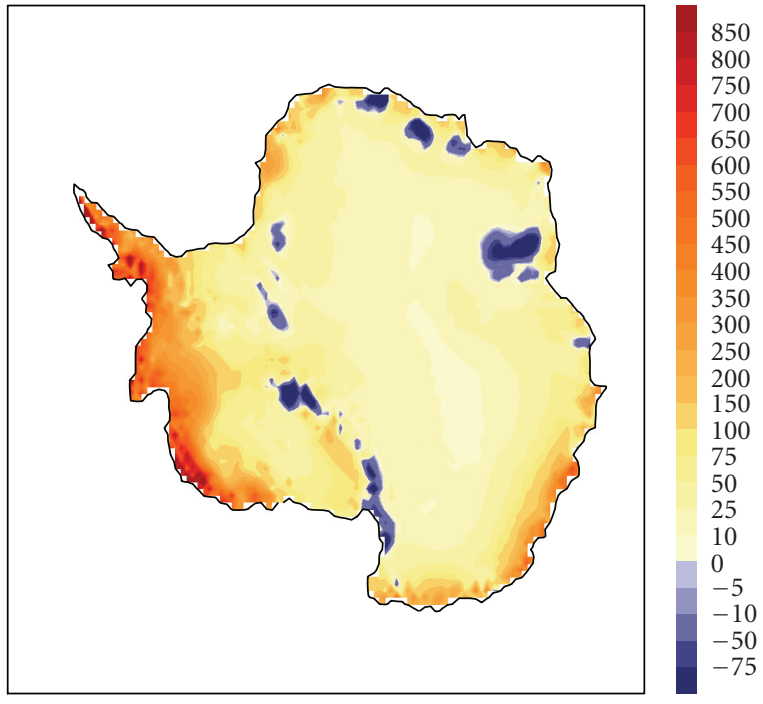

FIGURE 4: Annual net surface mass accumulation "precipitation minus sublimation (P-E)" ( $\mathrm{mm} /$ year) averaged over the time period 1958-1998 for HIRHAM.

largest annual precipitation (not shown) are found at the Western Antarctic Peninsula, coastal West Antarctica and coastal Wilkes Land due to the forced convection of the atmospheric flow over the ice-sheet topography. With the surface wind fields from the RCM simulations shown in Figure 2, the impact of drifting snow redistribution on snow accumulation is also assessed. The simulated HIRHAM accumulation fields along the Antarctic Peninsula and the coastal regions of the Bellingshausen and Amundsen Seas in West Antarctica are higher than those of Vaughan et al. [25]. Whereas the modelled accumulation is underestimated in the central Antarctic compared to Vaughan et al. [25], it is overestimated in the coastal areas, a feature detected and described also by Bromwich et al. [24] running the Polar MM5 model for the three years 1996-1999. The mean accumulation maps of Arthern et al. [26] are similar to previous compilations by Vaughan et al. [25] with high accumulation in coastal regions and very low accumulation rates in the interior of the continent. Compared to the former version of HIRHAM with only 19 levels (not shown) the increase to 25 levels reduces this underestimation over the inner Antarctic. Since HIRHAM computes the total cloud cover in a vertical column through a maximum random overlap, the vertical layering influences the total cloud cover and could impact on precipitation. As shown by Magand et al. [27] this underestimation of model accumulation on the Antarctic Plateau may reveal actual over estimation in the observations.

Raphael [28] showed that the SH high-latitude circulation shifted after 1975 into a new atmospheric circulation regime. Bromwich and Fogt [29] explained, that satellite radiances have been assimilated into ERA-40 reanalysis products beginning from 1979. Therefore the whole 40 year RCM simulation period from 1958 to 1998 was divided into 

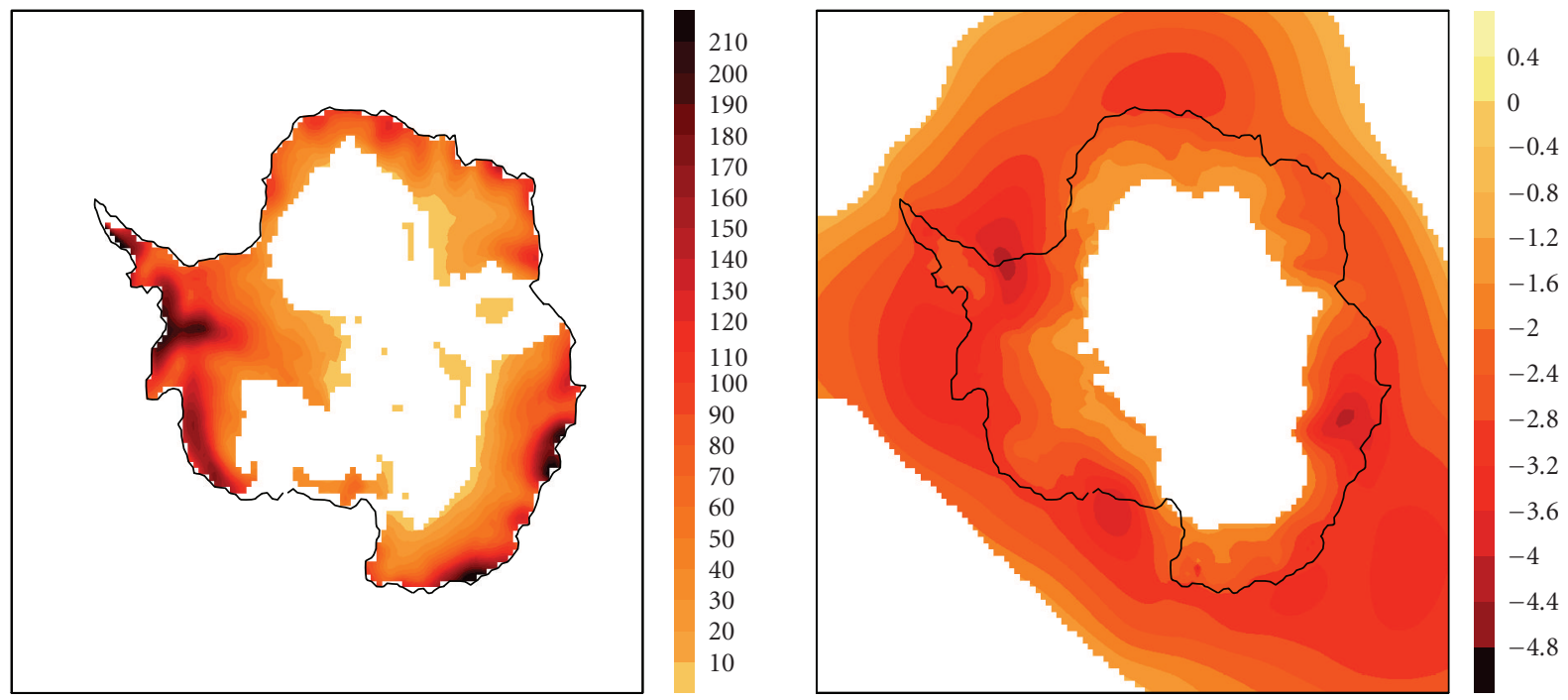

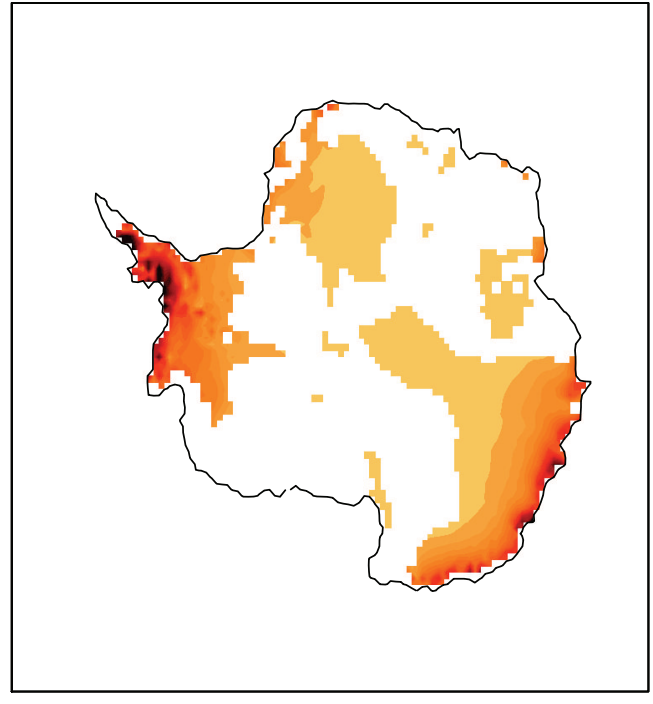

(a)

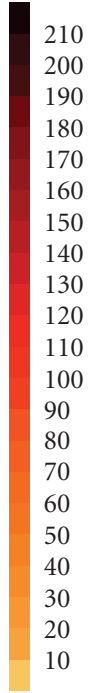

210
200
190
180
170
160
150
140
130
120
110
100
90
80
70
60
50
40
30
20
10

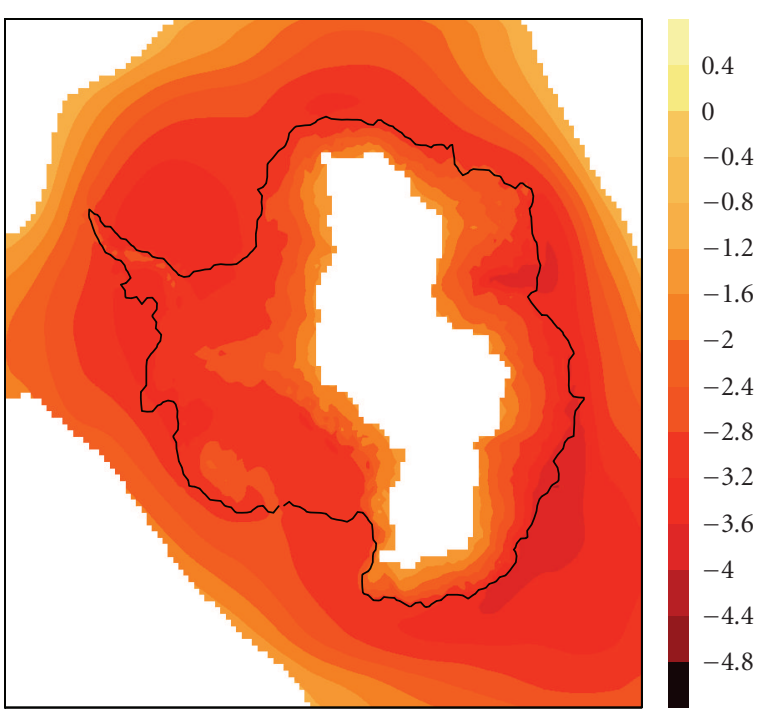

(b)

FIGURE 5: (a) Difference (S2 - S1) of the annual net surface mass accumulation "precipitation minus sublimation (P-E)" (mm/year), shaded. Time period S1: 1959-1978. Time period S2: 1979-1998. ERA-40 (top) and HIRHAM (bottom). The areas of significant changes above the $95 \%$ confidence level are indicated by contours. White spaces indicate regions with a confidence level below 95\%. (b) Difference (S2 - S1) of the annual mean sea level pressure (hPa). Time period S1: 1959-1978. Time period S2: 1979-1998. ERA-40 (top) and HIRHAM (bottom). The areas of significant changes above the $95 \%$ confidence level are indicated by contours. White spaces indicate regions with a confidence level below 95\%.

two 20-year-long records. In discussing the differences, we have to keep in mind, that in the first period the ERA-40 data are not constrained by satellites and the trends may be erroneous and contaminated as stated by Trenberth et al. [13].

Figure 5(a) presents the differences between the two 20-year-long time periods (1979-1998 "S2" minus 19591978 "S1") in the net mass accumulation from ERA-40 and HIRHAM simulations and their statistical significance. To determine the statistical significance of changes between the two time slices, a student's $t$-test with unequal variances for the mean sea level pressure (MSLP) and the net mass balance differences was used. Figure 5(b) shows the corresponding differences in the MSLP between both time slices and their statistical significances. Whereas the MSLP changes between ERA-40 and HIRHAM are quite similar, bigger differences occur in the accumulation pattern. The areas of statistical significant changes in HIRHAM are smaller and occur at the West Antarctic and South-East Antarctic coasts. The MSLP over the continent may be biased as a result of different topography between ERA40 and HIRHAM due to the extrapolation for pressure levels larger than $500 \mathrm{hPa}$. Since surface pressure over the Antarctic ice sheet is inhomogeneous, Genthon et al. [30] 
used the $500 \mathrm{hPa}$ geopotential height as the first level not affected by the Antarctic topography. Xin et al. [17] showed in a detailed study for three East Antarctic stations Mawson, Davis and Casey, that the HIRHAM simulations capture the meteorological evolution of the sea level pressure properly.

Pronounced precipitation driven changes in the surface mass balance on decadal time scales between the two time slices S1 and S2 appear which show only crude similarities at the Western and eastern Antarctic coasts comparing ERA-40 and the RCM simulations. The spatial differences between the two time slices are much higher in the ERA-40 reanalysis data compared to the HIRHAM simulations. In the RCM simulations, West Antarctica and East Antarctic coasts are influenced most strongly, whereas in the ERA-40 data also the Western inner part of Antarctica is impacted. The whole Western Antarctica and parts at Eastern Antarctica gain mass in the second period with more than $100 \mathrm{~mm} /$ year according to the HIRHAM simulations. The MSLP differences between both time periods around the Antarctic coasts of HIRHAM and ERA-40 match and indicates a pressure reduction in more recent time due to the shift towards a positive AAO phase. These pressure changes could be accompanied with changes of the transient surface pressure activity as suggested by Simmonds et al. [31], who discussed enhanced synoptic activity in the NCEP data for the time period 1979-2000 around Antarctica.

Figure 6 presents the net surface accumulation trends over the two 20-year-long time slices S1 and S2 and the whole period 1958-1998. The trends differ for both time slices. During S1 the trends are negative over most parts of Antarctica. But, since the ERA-40 data during this period are not constrained by satellites, the trends may be erroneous. During S2 there is an obvious shift to positive accumulation trends over inner Antarctica and the coast of Amundsen Sea. The trend over the whole period 1958-1998 is positive at the East Antarctic coasts as a result of a jump in the accumulation rates in the year 1979. The statistical significance of the accumulation trends is shown by indicating the values above the $95 \%$ confidence level. The significance of the trend was evaluated by the maximum likelihood estimator or equivalently by the generalized least squares estimator by Weatherhead et al. [32]. We assumed the commonly used decision rule that a significant trend is indicated, at the $95 \%$ confidence level, when $|A / B|>2$, where $A$ is a generalized least square estimator and $B$ is the standard error of $A$, based on Weatherhead et al. [32]. Trends in most regions of Antarctica are statistically significant with very pronounced changes between the two time slices, especially over the Antarctic Peninsula. A statistically significant accumulation trend over the Antarctic Peninsula is visible only in the whole 40 year period (Figure 6(c)). Stronger accumulation due to enhanced precipitation appears also over Western Antarctica and South-East Antarctica which could be connected with the increased cyclonic activity on time scales between 2-6 days computed and described on the basis of ERA-40 data in Figures 11 and 12. Figure 7 shows the accumulation trends for the shorter time slice 1992-2001, in qualitative agreement

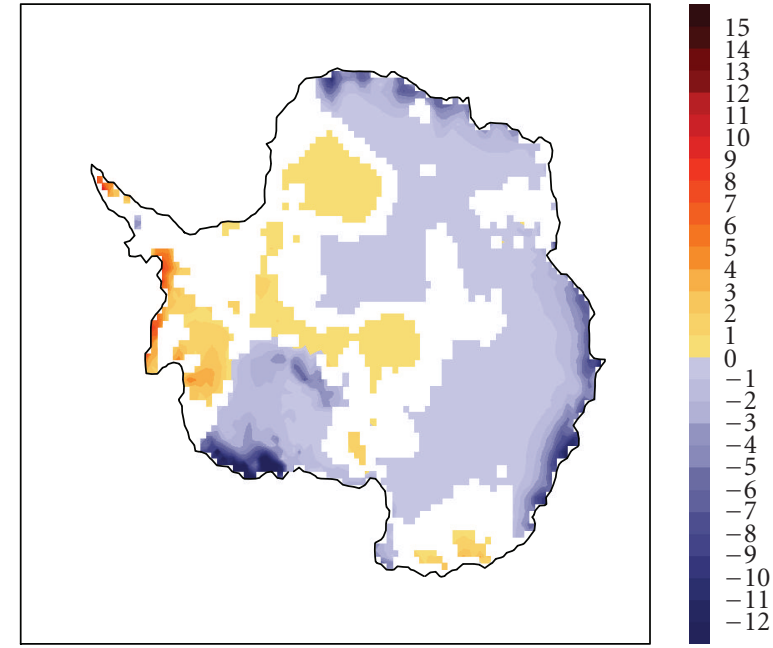

(a)

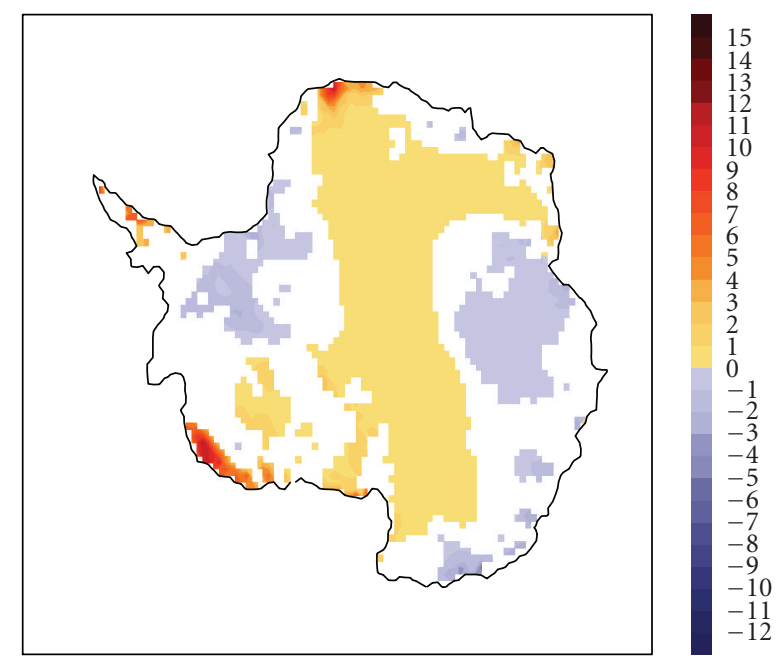

(b)

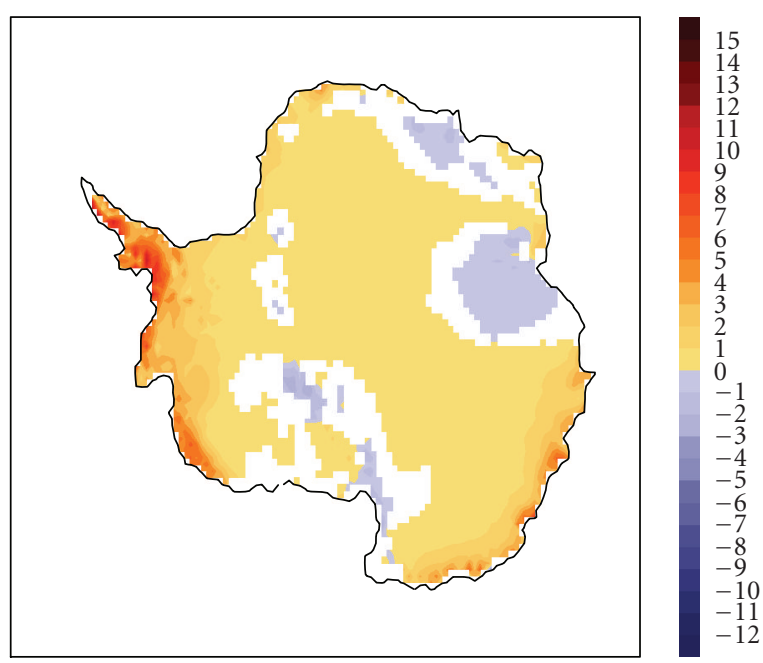

(c)

FIGURE 6: Annual accumulation trends $\left(\mathrm{mm} / \mathrm{year}^{2}\right)$ for S1: 19591978 (a), S2: 1979-1998 (b), and 1958-1998 (c) based on HIRHAM simulations. The areas of significant positive and negative changes above the $95 \%$ confidence level are indicated shaded. White spaces indicate regions with a confidence level below $95 \%$. 


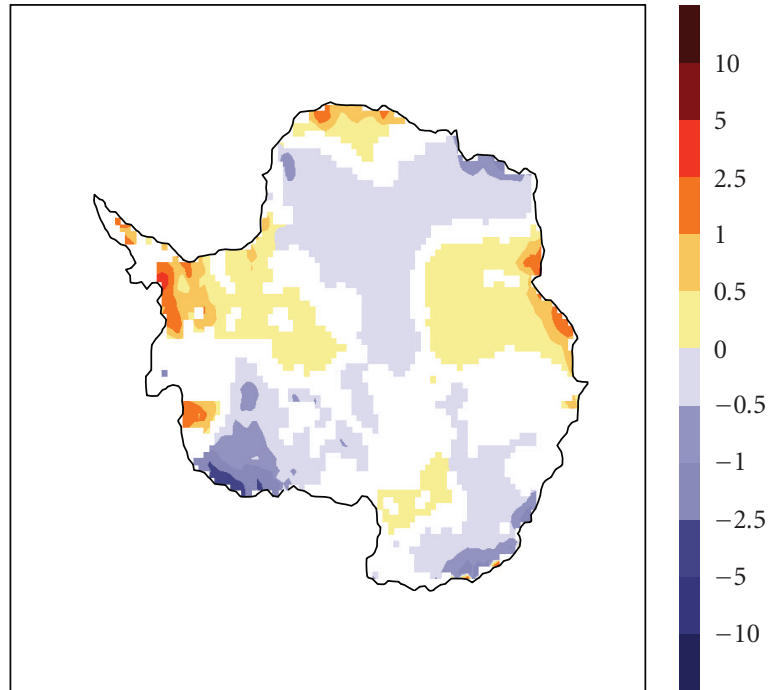

(a)

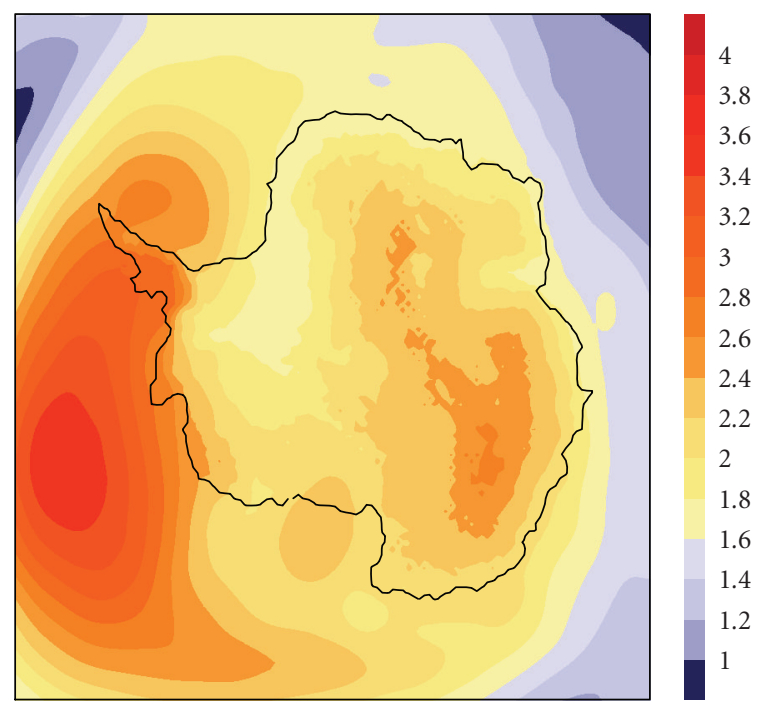

(b)

Figure 7: (a) Annual accumulation trends (mm/year ${ }^{2}$ ) for 19922001. HIRHAM simulations. The areas of significant positive or negative changes with $95 \%$ confidence are indicated. White regions describe areas below the 95\% significance level. (b) MSLP standard deviation (hPa) from 1992-2001, HIRHAM.

with the satellite-based estimates by Davis et al. [33] for the one-year-long period 1992-2002. Also shown is the MSLP standard deviation (stdev) as a measure for the strength of atmospheric transient processes partly driven by synopticscale processes. The highest stdev presented in Figure 7 on the bottom occur over in the Pacific Ocean over the Bellinghausen and Amundsen Sea. Obviously, the accumulation pattern show a high variability on interannual time scales, which are connected with changes in the transient pressure systems at least over the Antarctic Peninsula.

The annual mean sea level pressure trend from 1958 until 1998 based on ERA-40 and HIRHAM simulations presented

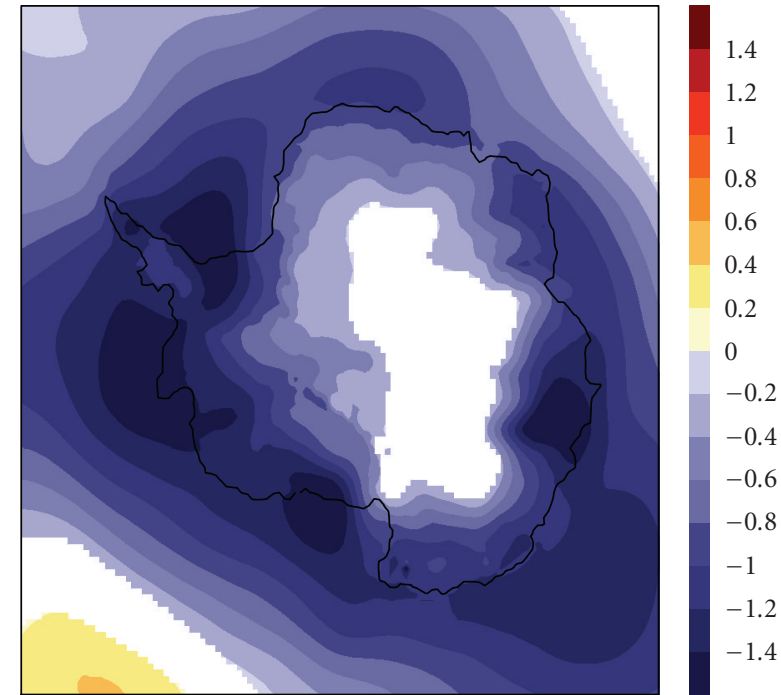

(a)

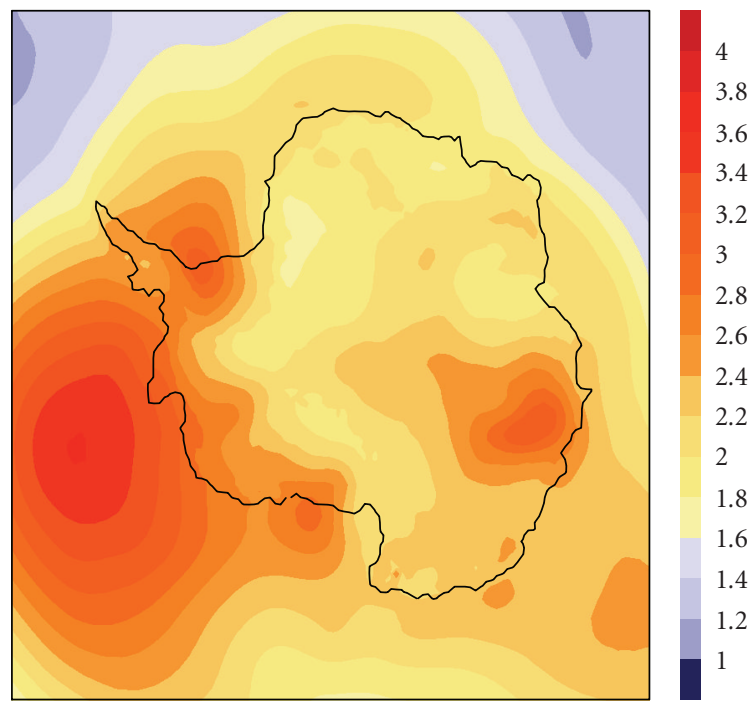

(b)

Figure 8: (a) Annual mean sea level pressure trends (hPa/decade) from 1958-1998, ERA-40. The areas of significant positive or negative changes with $95 \%$ confidence are indicated. White regions describe areas below the 95\% significance level. (b) MSLP standard deviation (hPa) from 1958-1998, ERA-40.

in Figures 8 and 9 indicates around the coasts a shift to more transient pressure systems and over inner Antarctica a strengthening of the high pressure anticyclone which is differently strong in ERA-40 and the RCM simulations. Displayed are also the stdev of the MSLP for ERA-40 and HIRHAM which both show a pronounced maximum over the Pacific Ocean. Lubin et al. [34] demonstrated that mesoscale cyclones have a significant dynamic effect on climate change over the Western Antarctic Peninsula and are associated with positive near-surface-air temperature anomalies. In the HIRHAM simulations presented in Figure 9 the pressure changes are connected with a warming 


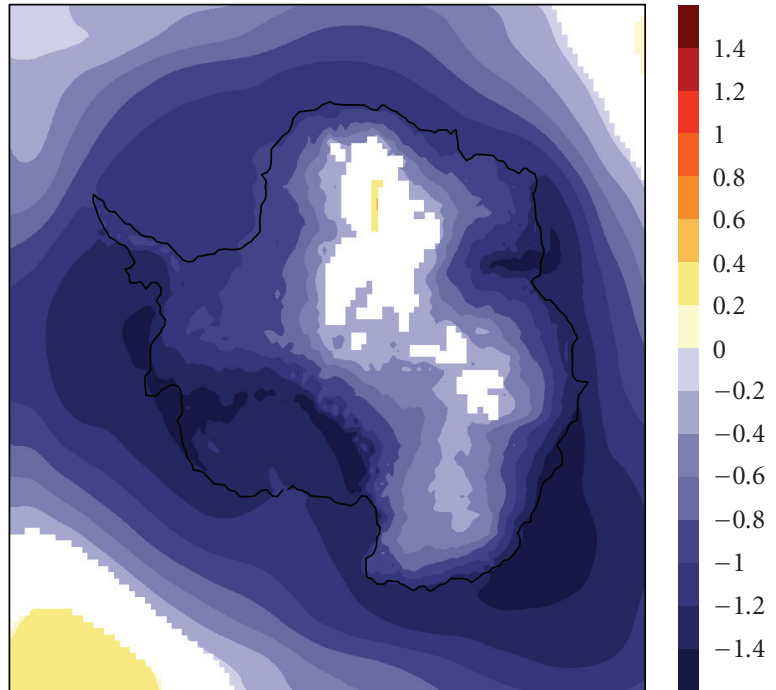

(a)

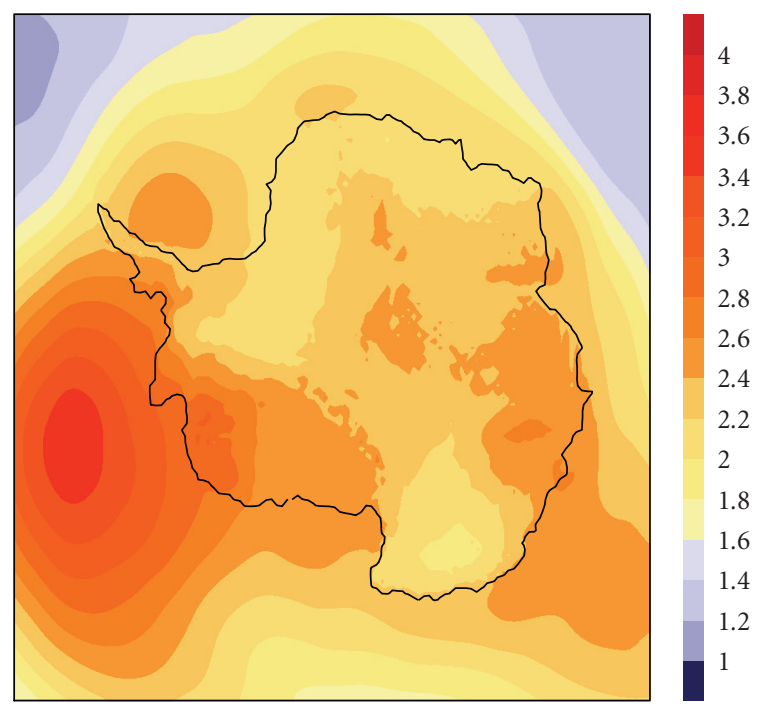

(b)

Figure 9: (a) Annual mean sea level pressure trends (hPa/decade) from 1958-1998, HIRHAM. The areas of significant positive or negative changes with $95 \%$ confidence are indicated. White regions describe areas below the 95\% significance level. (b) MSLP standard deviation (hPa) from 1958-1998, HIRHAM.

of the Antarctic Peninsula and a small cooling over East Antarctica. This connection is detectable in correlation maps of the $2 \mathrm{~m}$ temperature, MSLP and the net surface mass accumulation, for 1958-1998 based on the HIRHAM simulations, not shown. High pressure over the central Antarctic correlates with low temperatures there. Low pressure over the Antarctic Peninsula and East Antarctic coasts is connected with higher $2 \mathrm{~m}$ temperatures.

The location of the areas with positive accumulation trend is in agreement with a decreased sea level pressure, due to the strong connection between the transient pressure systems around Antarctica and accumulation changes. Enhanced synoptic activity in NCEP/NCAR reanalysis data

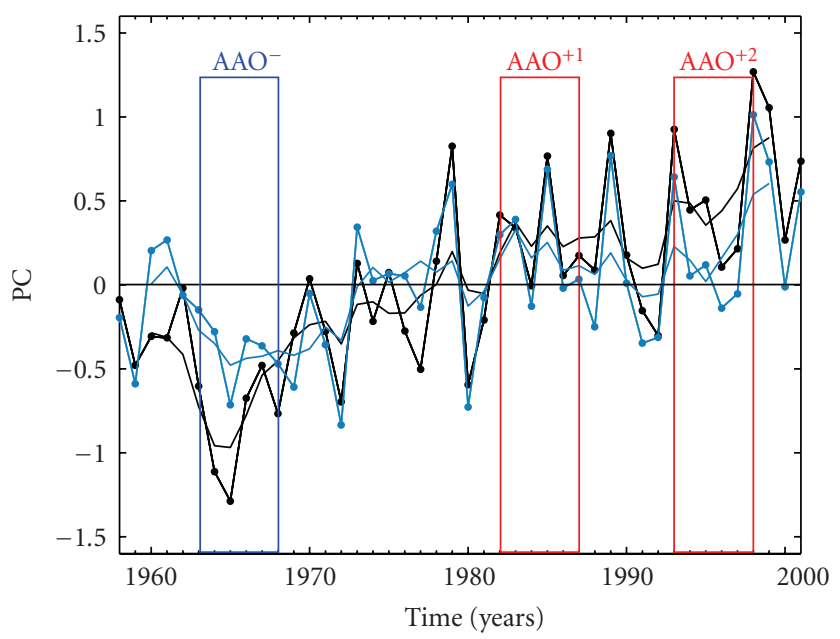

Figure 10: Time series of the yearly mean AAO index, 1958-2001 based on ERA-40 (blue) and NCEP data (black) at $850 \mathrm{hPa}$. The thin blue and black lines display the annual values and the thick blue and black lines the 5 year running mean. The positive AAO phases are indicated by red and the negative AAO phase by blue columns.

for the time period 1979-2000 was found by Simmonds et al. [31], who explored, that in the annual mean, cyclone intensity, radius and depth all show significant upward trends. The influence of transient pressure systems decreases inland and over the highest and coldest continental Antarctic regions the primary mode of precipitation is due to cooling of moist air just above the surface-based temperature inversion. This extremely cold air has little capacity to hold moisture, and thus the interior of the East Antarctic ice sheet is a polar desert, as illustrated by Figures 3 and 4 .

3.2. AAO Pattern and Storm Tracks. As attested by Gong and Wang [6] the AAO pattern exists over the whole year with strongest changes during summer. Figure 10 shows the time series of the yearly mean AAO Index for 1958-2001 computed from the NCEP/NCAR reanalysis and the ERA40 from the $850 \mathrm{hPa}$ geopotential height fields. The thin blue and black lines display the annual values and the thick blue and black lines the 5 year running mean. Although there are obvious differences between both reanalysis data sets, the selected positive and negative AAO phases are in agreement. Genthon et al. [35] made a similar comparison using sea level pressure data and got even a better correlation.

One time slice for a negative AAO phase between 1963 and $1968\left(\mathrm{AAO}^{-}\right)$and two positive $\mathrm{AAO}$ phases between 1982-1987 $\left(\mathrm{AAO}^{+1}\right)$ and 1993-1998 $\left(\mathrm{AAO}^{+2}\right)$ have been selected. The origin of the apparent shift to a positive phase is under discussion and explained by increased greenhouse gas forcing [36], stratospheric ozone decrease [37] and changes in the tropical sea surface temperatures in the Pacific Ocean [8]. Recent studies have suggested that the largest contributing factor to the shift in the AAO has been the stratospheric ozone hole, followed by increasing greenhouse gases and then natural forcing. 


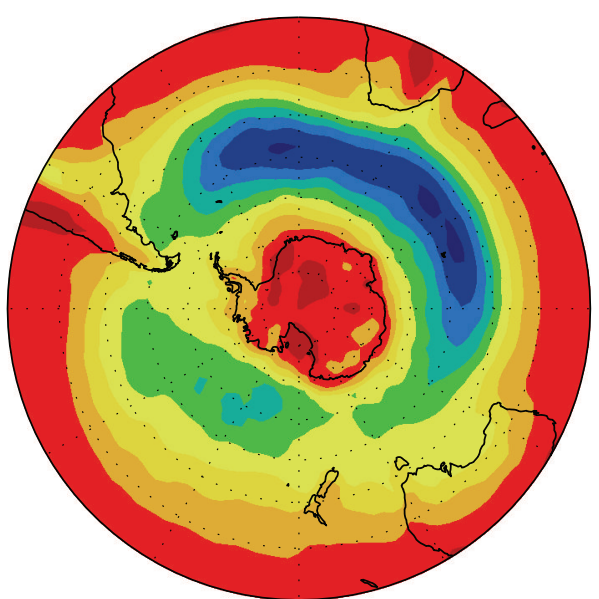

(a)

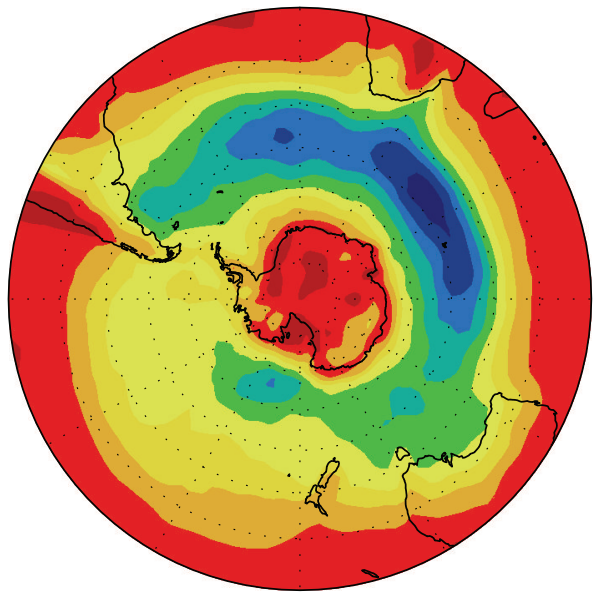

(c)

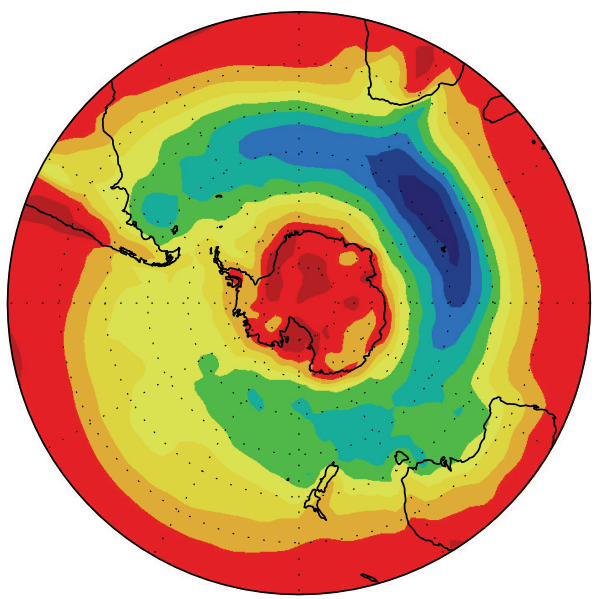

(e)
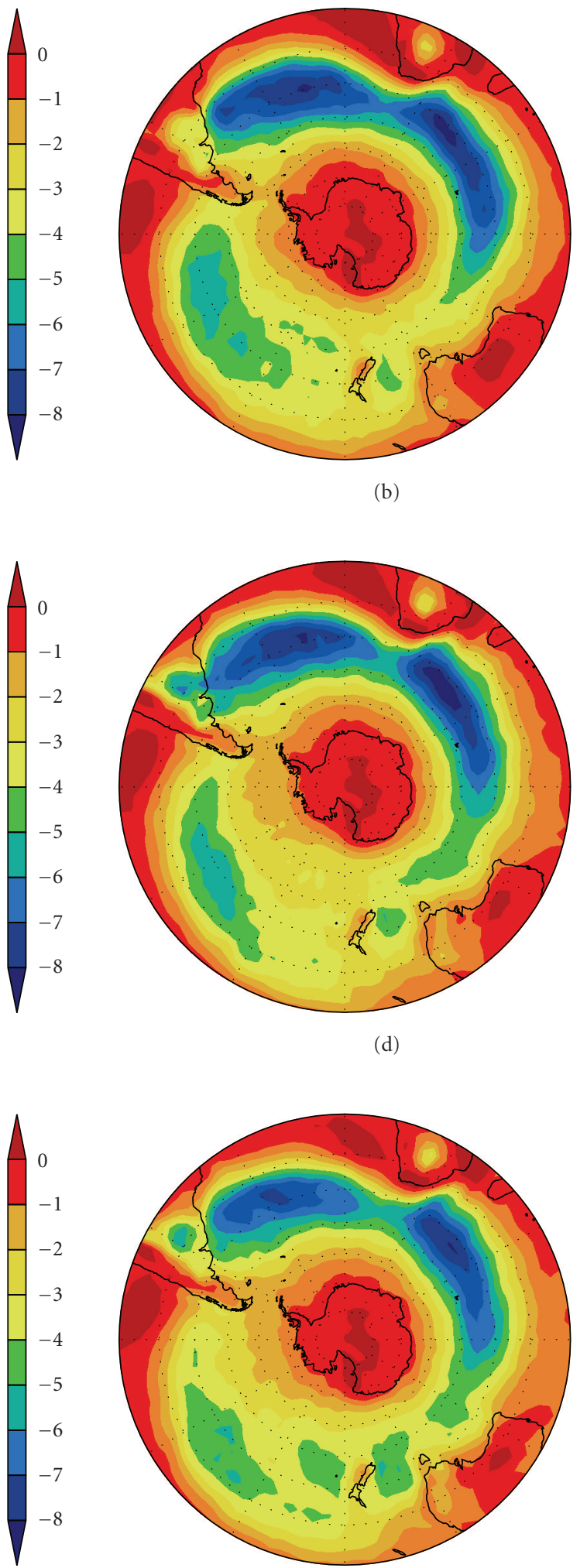

(f)

(b)

(d)
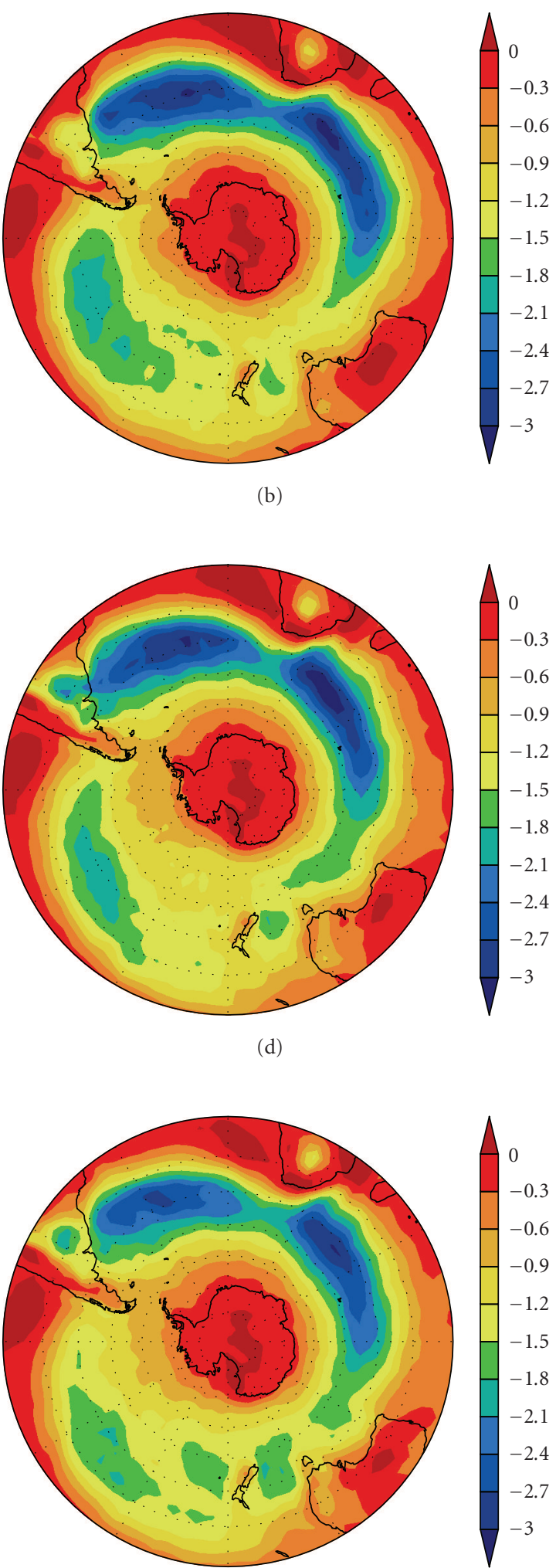

Figure 11: Baroclinic heat fluxes $\left((\mathrm{a}, \mathrm{c}, \mathrm{e}), \mathrm{ms}^{-1} \mathrm{~K}\right)$ and humidity fluxes $\left((\mathrm{b}, \mathrm{d}, \mathrm{f}), 10^{-3} \mathrm{~ms}^{-1} \mathrm{~kg} / \mathrm{kg}\right)$ on time scales $2-6$ days at $850 \mathrm{hPa}$ for the three AAO time slices $\mathrm{AAO}^{-}(\mathrm{a})$ and (b), and $\mathrm{AAO}^{+1}$ (c) and (d), $\mathrm{AAO}^{+2}$ (e) and (f) based on ERA-40 data. 


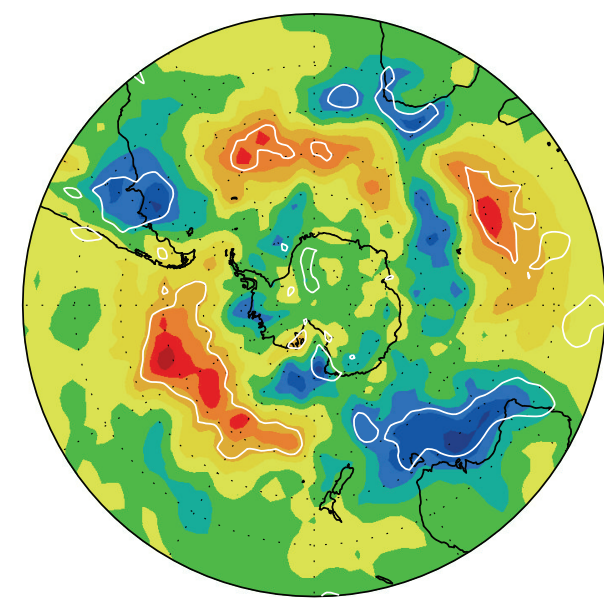

(a)

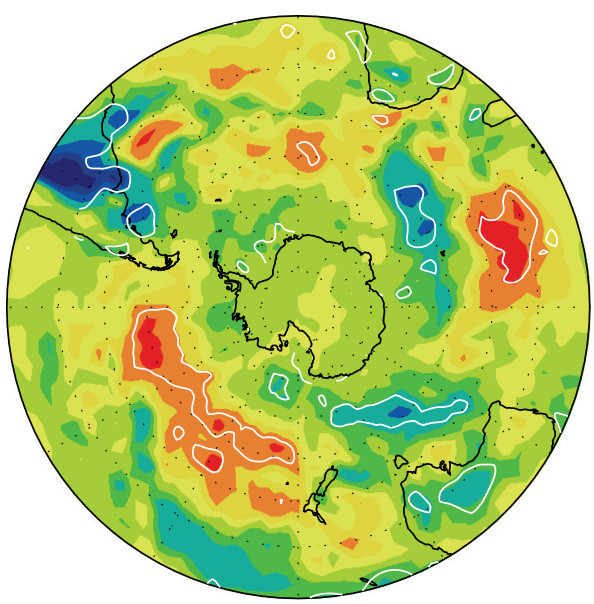

(c)
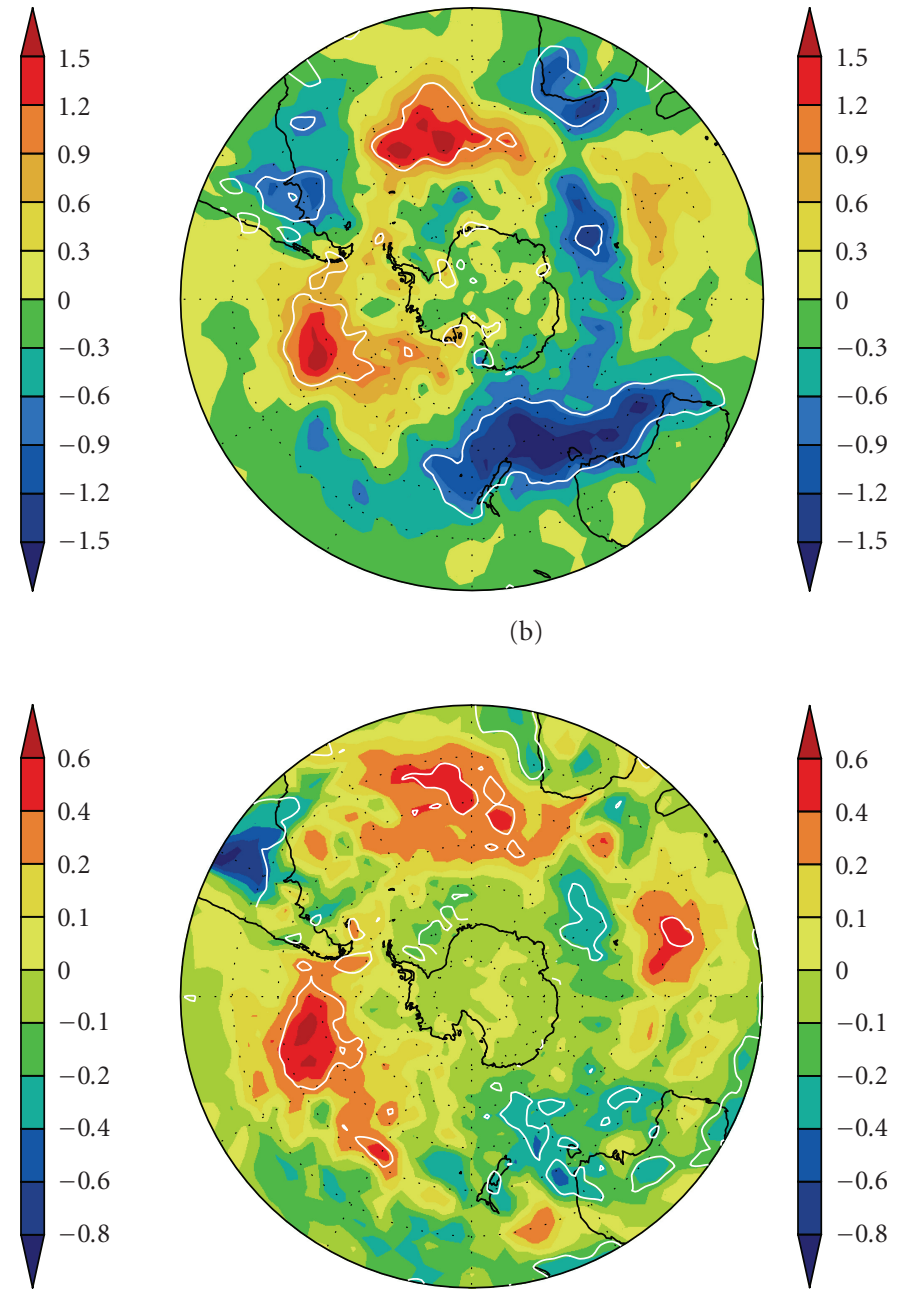

(d)

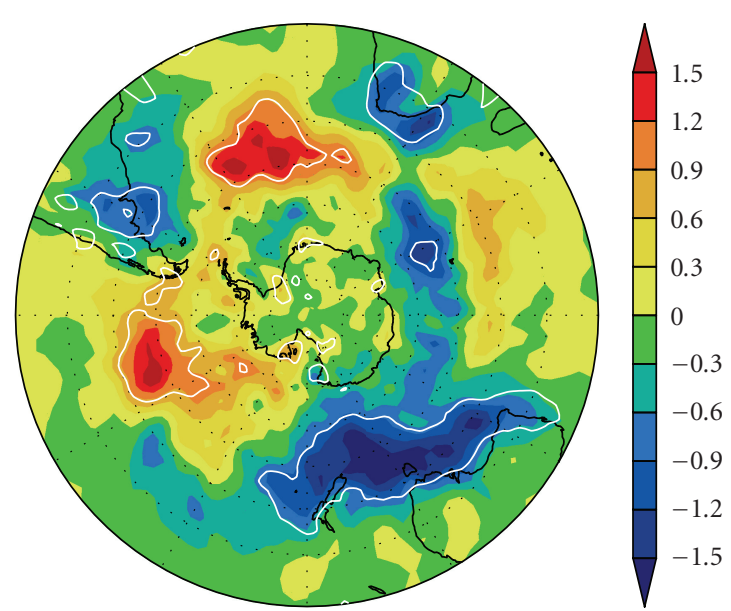

(b)

Figure 12: Differences of baroclinic heat fluxes ((a) and (b), $\left.\mathrm{ms}^{-1} \mathrm{~K}\right)$ and humidity fluxes ((c) and (d), $\left.10^{-3} \mathrm{~ms}^{-1} \mathrm{~kg} / \mathrm{kg}\right)$ on time scales 2-6 days at $850 \mathrm{hPa}$ between positive and negative AAO time slices based on ERA-40 data. Differences $\left(\mathrm{AAO}^{+1}-\mathrm{AAO}^{-}\right)$left. Differences $\left(\mathrm{AAO}^{+2}-\mathrm{AAO}^{-}\right)$right.

A widely used method for the determination of the most dominant, linearly uncorrelated spatial and temporal structures of the atmospheric circulation is the empirical orthogonal function (EOF) analysis, described, for example, in Handorf and Dethloff [38]. The computed AAO pattern for the three time slices indicate the pronounced changes of the global pattern in the $\mathrm{SH}$, not shown.

These changes in the global AAO pattern are connected with changes in the baroclinic heat and humidity fluxes on time scales 2-6 days at $850 \mathrm{hPa}$ as discussed by Sokolova et al. [39]. The low-frequency eddies with characteristic time scales $>10$ days and the high-frequency eddies with time scales $<10$ days are separated by applying a time filter and their interaction with the time-averaged latitude and longitude-dependent mean atmospheric circulation state can be described and analysed. Analyses of the $500 \mathrm{hPa}$ geopotential heights by Wallace and Blackmon [40] showed that a low-pass filter acts similar to a space filter, since the ultralong waves with wave numbers $>4$ explain the biggest part of the observed low-frequency variance, whereas the high-frequency eddies with periods between 2 and 6 days are mainly connected with the shorter baroclinic waves. The synoptic-scale heat and humidity fluxes on these time scales for the three AAO time slices computed on the ERA-40 data are presented in Figure 11. The poleward directed heat and humidity fluxes are described by negative values and show maxima over the Pacific and Atlantic Oceans. Tietäväinen and Vihma [41] analysed the atmospheric moisture budget over Antarctica and the Southern Ocean for the period 19792001 on the basis of the ERA-40 reanalysis. They showed that the meridional transport by transient eddies makes the largest contribution to the southward water vapour transport.

The difference plots for the heat and humidity fluxes between the positive and negative AAO periods show strongest changes over the Oceans surrounding Antarctica, displayed in Figure 12. During both positive AAO phases increased heat and humidity transports due to synoptical 


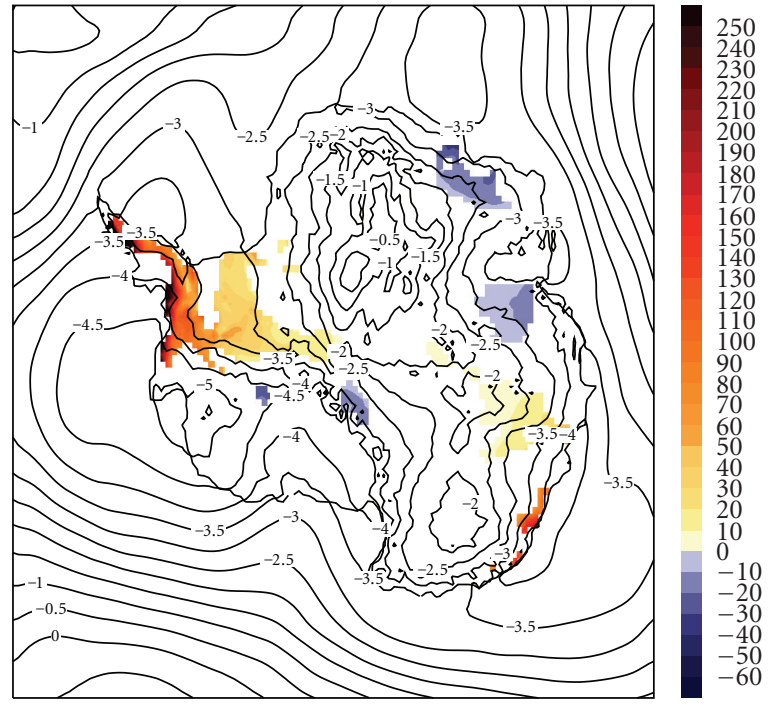

(a)

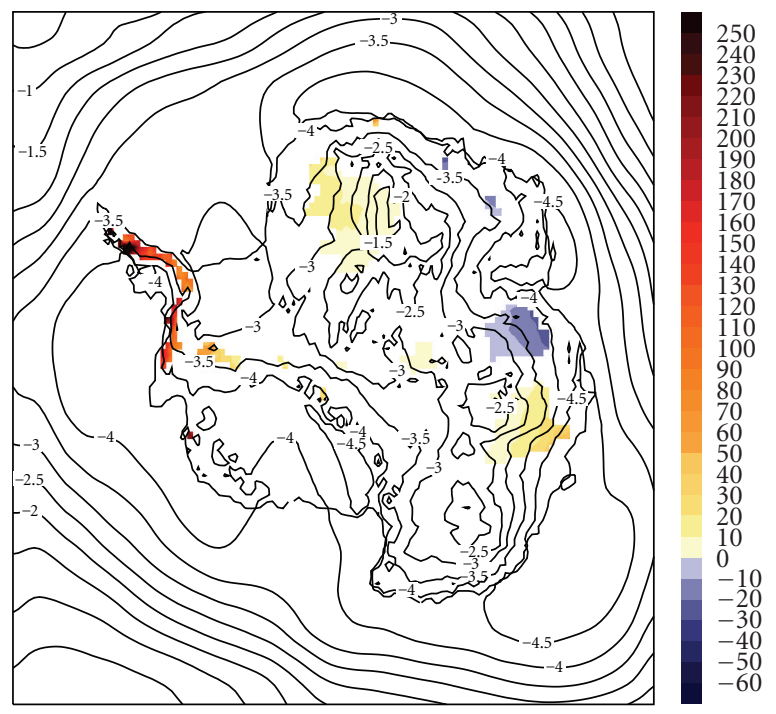

(b)

FIGURE 13: Net surface mass balance (mm/year) " $\mathrm{AAO}^{+1}$ minus $\mathrm{AAO}^{-}$" years (a) and the "AAO ${ }^{+2}$ minus $\mathrm{AAO}^{-}$" years (b), based on HIRHAM simulations in colours. The corresponding differences in annually averaged mean sea level pressure (hPa) are shown as isolines. The areas of significant positive and negative changes above the $95 \%$ confidence level are indicated by colour. White spaces indicate regions with a confidence level below $95 \%$.

cyclones at $850 \mathrm{hPa}$ toward the Antarctic continent appear over the Pacific Ocean. Over the Atlantic Ocean a reduction occurs. The changes between the AAO phases in the regions indicated by white contours are statistical significant above the $95 \%$ level.

Figure 13 shows the net mass accumulation and mean sea level pressure differences between the positive and negative $\mathrm{AAO}$ phases " $\mathrm{AAO}^{+1}$ minus $\mathrm{AAO}^{-}$" and the " $\mathrm{AAO}^{+2}$ minus $\mathrm{AAO}^{-"}$. In comparing the changes for different AAO time slices a linear approach have been assumed. But as shown by Brand et al. [42], for example, tropo-stratospheric feedbacks owing to an interactive stratospheric ozone chemistry influence the tropospheric AAO phases in a highly nonlinear way.

The circulation changes between these two positive AAO phases compared to the negative phase indicate a reduction of the sea level pressure over the coastal regions of Antarctica. A pronounced pressure decrease of $-5 \mathrm{hPa}$ occurs in the Amundsen Sea and another pressure decrease of about $-4 \mathrm{hPa}$ is visible at the coasts of Wilkes Land. Due to the reduced meridional air mass exchange in positive AAO phases a sea level pressure descent occurs accompanied by pronounced cooling and drying over continental Antarctica. The second, positive AAO phase imprints with a much stronger pressure decrease as a result of increased transient processes around the Antarctic coasts compared to the first positive AAO phase. The contribution due to synoptic pressure cyclones on time scales between 2-6 days in the RCM simulations has to be clarified in further investigations. In both positive AAO phases enhanced statistically significant accumulation occurs over the Antarctic Peninsula. The accumulation is stronger during the first AAO period from 19821987. During the positive AAO phases a strong cooling over most of East Antarctica and a warming over the Antarctic Peninsula is induced (not shown), which is in agreement with the results of Van de Berg et al. [10]. The strong pressure decrease during the second positive AAO phase influences the cyclone tracks around Antarctica and the accumulation pattern shown in Figure 13. During the positive AAO phases the Antarctic Peninsula becomes wetter, while parts of East Antarctica becomes drier. The accumulation response differs regionally between the two positive $\mathrm{AAO}$ phases and the strength of polar desertification weakened in the last AAO phase. Figure 6 showed a negative accumulation trend over the Lambert Glacier which persists over the simulated 4 decades and is connected with a statistically significant negative surface mass balance during both AAO phases in the same area, presented in Figure 13.

\section{Conclusions}

Our results indicated that there is a substantial amount of spatial and temporal variability in the Antarctic surface mass balance. The HIRHAM simulations overestimate the mass accumulation at the West and East-Antarctic coasts and underestimate it over the inner Antarctic in agreement with Van de Berg et al. [10]. The annual variability and trends over Antarctica are the small residual of larger seasonal variability and trends that appear to be related to recent climate change, particularly seasonally varying trends in the AAO. Though considerable changes happen regionally, averaged over Antarctica, the trend in Antarctic precipitation, appears to be small and is in the order of $0.79 \mathrm{~cm} /$ decade.

The annual mean sea level pressure trend from 1958 until 1998 based on ERA-40 and HIRHAM simulations indicates around the coasts a shift to more transient low pressure systems. In terms of surface temperature changes these pressure changes are connected with a warming of 
the Antarctic Peninsula and a small cooling around the coast of East Antarctica. The location of the areas with positive precipitation trend is in agreement with a decreased sea level pressure, due to the strong connection between the transient pressure activity around Antarctica and accumulation changes which are in most regions of Antarctica statistically significant. The strongest positive accumulation changes occur over the Antarctic Peninsula and the coastal parts of Western and Eastern Antarctica. Both AAO phases show enhanced statistically significant accumulation over the Antarctic Peninsula being stronger for the first AAO period and reduced accumulation over the Lambert Glacier in East Antarctica.

Due to the reduced meridional air mass exchange in positive AAO phases a sea level pressure descent occurs accompanied by pronounced cooling and drying over continental Antarctica. The more recent positive AAO phase imprints with a much stronger pressure decrease as a result of increased transient pressure processes around the Antarctic coasts compared to the first positive AAO phase. The ERA-40 data show a pronounced increase in the heat and humidity fluxes in $850 \mathrm{hPa}$ over the Pacific Ocean due to baroclinic pressure systems on time scales between 2-6 days during positive AAO phases.

The current study focused on evaluation of atmospheric circulation, precipitation and accumulation processes and the mass balance of the ice sheet based on the HIRHAM4 physical parameterizations. Further improvements of atmospheric process parameterizations are required especially in sub-grid-scale cloud properties and radiative effects. This will be done by implementing the further developed parameterization schemes of the ECHAM5 general atmospheric circulation model into the HIRHAM RCM.

\section{Acknowledgments}

The authors thank Ines Hebestadt and Sabine Erxleben for model simulation support and data handling during this project. The authors appreciate financial support from the Deutsche Forschungsgemeinschaft (DFG) under Grant DE 635. The authors acknowledge the advices of three anonymous reviewers who helped to improve and clarify the paper.

\section{References}

[1] P. T. Doran, J. C. Priscu, W. Berry Lyons, et al., "Antarctic climate cooling and terrestrial ecosystem response," Nature, vol. 415, no. 6871, pp. 517-520, 2002.

[2] E. J. Steig, D. P. Schneider, S. D. Rutherford, M. E. Mann, J. C. Comiso, and D. T. Shindell, "Warming of the Antarctic icesheet surface since the 1957 International Geophysical Year," Nature, vol. 457, no. 7228, pp. 459-462, 2009.

[3] S. S. Jacobs and J. C. Comiso, "Climate variability in the Amundsen and Bellingshausen Seas," Journal of Climate, vol. 10, no. 4, pp. 697-709, 1997.

[4] D. G. Vaughan, G. J. Marshall, W. M. Connolley, J. C. King, and R. Mulvaney, "Devil in the detail," Science, vol. 293, no. 5536, pp. 1777-1779, 2001.
[5] W. M. Connolley and S. P. O’Farrell, “Comparison of warming trends over the last century around Antarctica from three coupled models," Annals of Glaciology, vol. 27, pp. 565-570, 1998.

[6] D. Gong and S. Wang, "Definition of Antarctic oscillation index," Geophysical Research Letters, vol. 26, no. 4, pp. 459462, 1999.

[7] N. P. Gillett and D. W. J. Thompson, "Simulation of recent Southern Hemisphere climate change," Science, vol. 302, no. 5643, pp. 273-275, 2003.

[8] R. L. Fogt and D. H. Bromwich, "Decadal variability of the ENSO teleconnection to the high-latitude south pacific governed by coupling with the Southern Annular Mode," Journal of Climate, vol. 19, no. 6, pp. 979-997, 2006.

[9] G. J. Marshall, A. Orr, N. P. M. van Lipzig, and J. C. King, "The impact of a changing Southern Hemisphere Annular Mode on Antarctic Peninsula summer temperatures," Journal of Climate, vol. 19, no. 20, pp. 5388-5404, 2006.

[10] W. J. van de Berg, M. R. van den Broeke, C. H. Reijmer, and E. van Meijgaard, "Characteristics of the Antarctic surface mass balance, 1958-2002, using a regional atmospheric climate model," Annals of Glaciology, vol. 41, pp. 97-104, 2005.

[11] G. Krinner, B. Guicherd, K. Ox, C. Genthon, and O. Magand, "Influence of oceanic boundary conditions in simulations of antarctic climate and surface mass balance change during the coming century," Journal of Climate, vol. 21, no. 5, pp. 938$962,2008$.

[12] A. J. Monaghan, D. H. Bromwich, and S.-H. Wang, "Recent trends in Antarctic snow accumulation from Polar MM5 simulations," Philosophical Transactions of the Royal Society A, vol. 364, no. 1844, pp. 1683-1708, 2006.

[13] K. E. Trenberth, D. P. Stepaniak, and L. Smith, "Interannual variability of patterns of atmospheric mass distribution," Journal of Climate, vol. 18, no. 15, pp. 2812-2825, 2005.

[14] P. D. Jones and D. H. Lister, "Intercomparison of our different Southern Hemisphere sea level pressure datasets," Geophysical Research Letters, vol. 34, no. 10, Article ID L10704, 2007.

[15] K. Dethloff, A. Rinke, R. Lehmann, J. H. Christensen, M. Botzet, and B. Machenhauer, "Regional climate model of the Arctic atmosphere," Journal of Geophysical Research D, vol. 101, no. 18, pp. 23401-23422, 1996.

[16] A. Rinke, P. Marbaix, and K. Dethloff, "Internal variability in Arctic regional climate simulations: case study for the SHEBA year," Climate Research, vol. 27, no. 3, pp. 197-209, 2004.

[17] Y. Xin, A. Rinke, L. Bian, K. Dethloff, C. Xiao, and M. Mielke, "Climate and forecast mode simulations for Antarctica: implications for temperature and wind," Advances in Atmospheric Sciences. In press.

[18] S. M. Uppala, P. W. Kallberg, A. J. Simmons, et al., "The ERA40 re-analysis," Quarterly Journal of the Royal Meteorological Society, vol. 131, no. 612, pp. 2961-3012, 2005.

[19] G. J. Marshall, "Trends in the Southern Annular Mode from observations and reanalyses," Journal of Climate, vol. 16, no. 24, pp. 4134-4143, 2003.

[20] H. Von Storch, H. Langenberg, and F. Feser, "A spectral nudging technique for dynamical downscaling purposes," Monthly Weather Review, vol. 128, no. 10, pp. 3664-3673, 2000.

[21] E. Roeckner, K. Arpe, L. Bengtsson, et al., "The atmospheric general circulation model ECHAM4: model description and simulation of present-day climate," MPI Report 218, Max Planck Inst. for Meteorology, Hamburg, Germany, 1996. 
[22] A. Rinke and K. Dethloff, "On the sensitivity of a regional Arctic climate model to initial and boundary conditions," Climate Research, vol. 14, no. 2, pp. 101-113, 2000.

[23] W. Wu, A. H. Lynch, and A. Rivers, "Estimating the uncertainty in a regional climate model related to initial and lateral boundary conditions," Journal of Climate, vol. 18, no. 7, pp. 917-933, 2005.

[24] D. H. Bromwich, Z. Guo, L. Bai, and Q.-S. Chen, "Modeled Antarctic precipitation. Part I: spatial and temporal variability," Journal of Climate, vol. 17, no. 3, pp. 427-447, 2004.

[25] D. G. Vaughan, J. L. Bamber, M. Giovinetto, J. Russell, and A. P. R. Cooper, "Reassessment of net surface mass balance in Antarctica," Journal of Climate, vol. 12, no. 4, pp. 933-946, 1999.

[26] R. J. Arthern, D. P. Winebrenner, and D. G. Vaughan, "Antarctic snow accumulation mapped using polarization of 4.3$\mathrm{cm}$ wavelength microwave emission," Journal of Geophysical Research D, vol. 111, no. 6, Article ID D06107, 2006.

[27] O. Magand, C. Genthon, M. Fily, et al., "An up-to-date quality-controlled surface mass balance data set for the $90^{\circ}-$ $180^{\circ} \mathrm{E}$ Antarctica sector and 1950-2005 period," Journal of Geophysical Research D, vol. 112, no. 12, Article ID D12106, 2007.

[28] M. Raphael, "Recent, large-scale changes in the extratropical Southern Hemisphere atmospheric circulation," Journal of Climate, vol. 16, no. 17, pp. 2915-2924, 2003.

[29] D. H. Bromwich and R. L. Fogt, "Strong trends in the skill of the ERA-40 and NCEP-NCAR reanalyses in the high and midlatitudes of the Southern Hemisphere, 1958-2001," Journal of Climate, vol. 17, no. 23, pp. 4603-4620, 2004.

[30] C. Genthon, G. Krinner, and M. Sacchettini, "Interannual Antarctic tropospheric circulation and precipitation variability," Climate Dynamics, vol. 21, no. 3-4, pp. 289-307, 2003.

[31] I. Simmonds, K. Keay, and E.-P. Lim, "Synoptic activity in the seas around Antarctica," Monthly Weather Review, vol. 131, no. 2, pp. 272-288, 2003.

[32] E. C. Weatherhead, A. J. Stevermer, and B. E. Schwartz, "Detecting environmental changes and trends," Physics and Chemistry of the Earth, vol. 27, no. 6-8, pp. 399-403, 2002.

[33] C. H. Davis, Y. Li, J. R. McConnell, M. M. Frey, and E. Hanna, "Snowfall-driven growth in East Antarctic ice sheet mitigates recent sea-level rise," Science, vol. 308, no. 5730, pp. 18981901, 2005.

[34] D. Lubin, R. A. Wittenmyer, D. H. Bromwich, and G. J. Marshall, "Antarctic Peninsula mesoscale cyclone variability and climatic impacts influenced by the SAM," Geophysical Research Letters, vol. 35, no. 2, Article ID L02808, 2008.

[35] C. Genthon, S. Kaspari, and P. A. Mayewski, "Interannual variability of the surface mass balance of West Antarctica from ITASE cores and ERA40 reanalyses, 1958-2000," Climate Dynamics, vol. 24, no. 7-8, pp. 759-770, 2005.

[36] W. Cai, P. H. Whetton, and D. J. Karoly, "The response of the Antarctic Oscillation to increasing and stabilized atmospheric $\mathrm{Co}_{2}$," Journal of Climate, vol. 16, no. 10, pp. 1525-1538, 2003.

[37] D. W. J. Thompson and S. Solomon, "Interpretation of recent Southern Hemisphere climate change," Science, vol. 296, no. 5569, pp. 895-899, 2002.

[38] D. Handorf and K. Dethloff, "Atmospheric teleconnections and flow regimes under future climate projections," European Physical Journal: Special Topics, vol. 174, no. 1, pp. 237-255, 2009.
[39] E. Sokolova, K. Dethloff, A. Rinke, and A. Benkel, "Planetary and synoptic scale adjustment of the Arctic atmosphere to sea ice cover changes," Geophysical Research Letters, vol. 34, no. 17, Article ID L17816, 2007.

[40] J. M. Wallace and M. L. Blackmon, "Observations of low frequency atmospheric variability," in Large-Scale Dynamical Processes in the Atmosphere, B. Hoskins and R. Pearce, Eds., pp. 55-94, Academic Press, New York, NY, USA, 1983.

[41] H. Tietäväinen and T. Vihma, "Atmospheric moisture budget over Antarctica and the Southern Ocean based on the ERA40 reanalysis," International Journal of Climatology, vol. 28, no. 15, pp. 1977-1995, 2008.

[42] S. Brand, K. Dethloff, and D. Handorf, "The Antarctic Oscillation structure in an AOGCM with interactive stratospheric chemistry," submitted to Atmospheric Science Letters. 

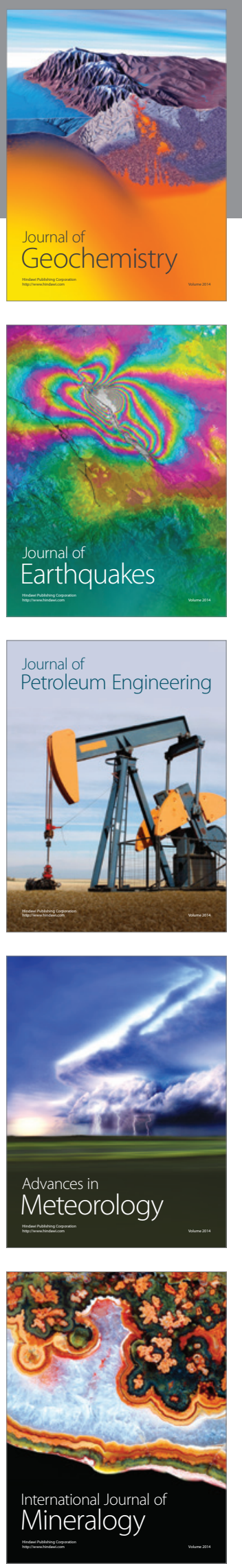
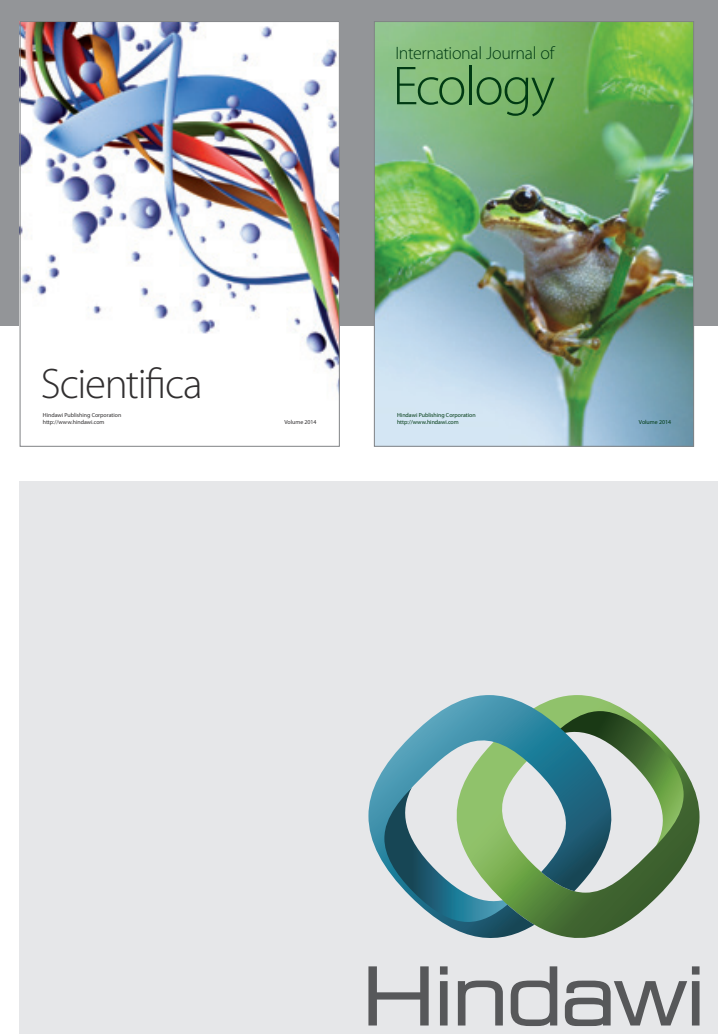

Submit your manuscripts at http://www.hindawi.com
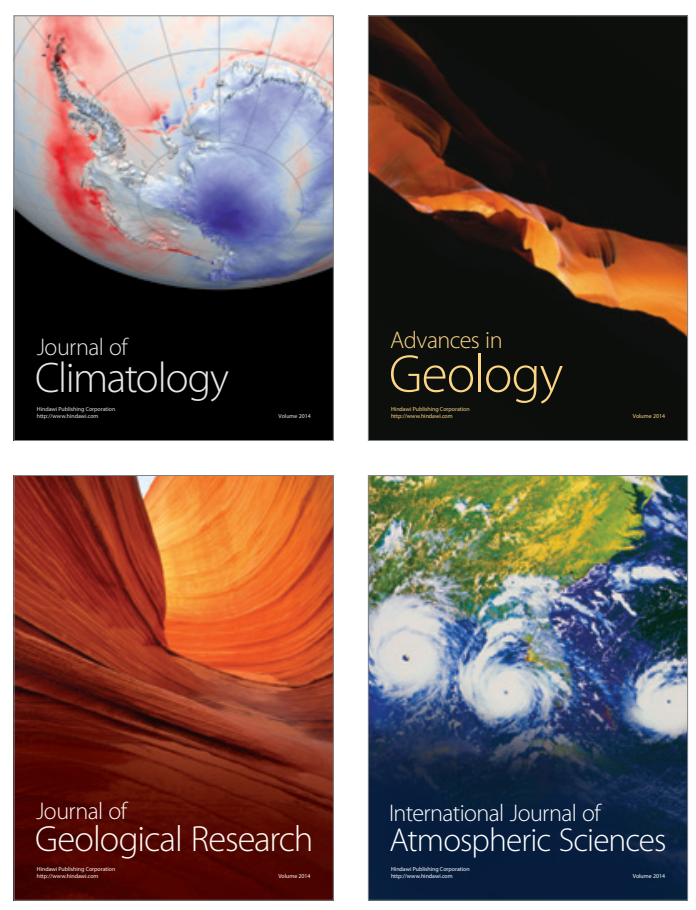
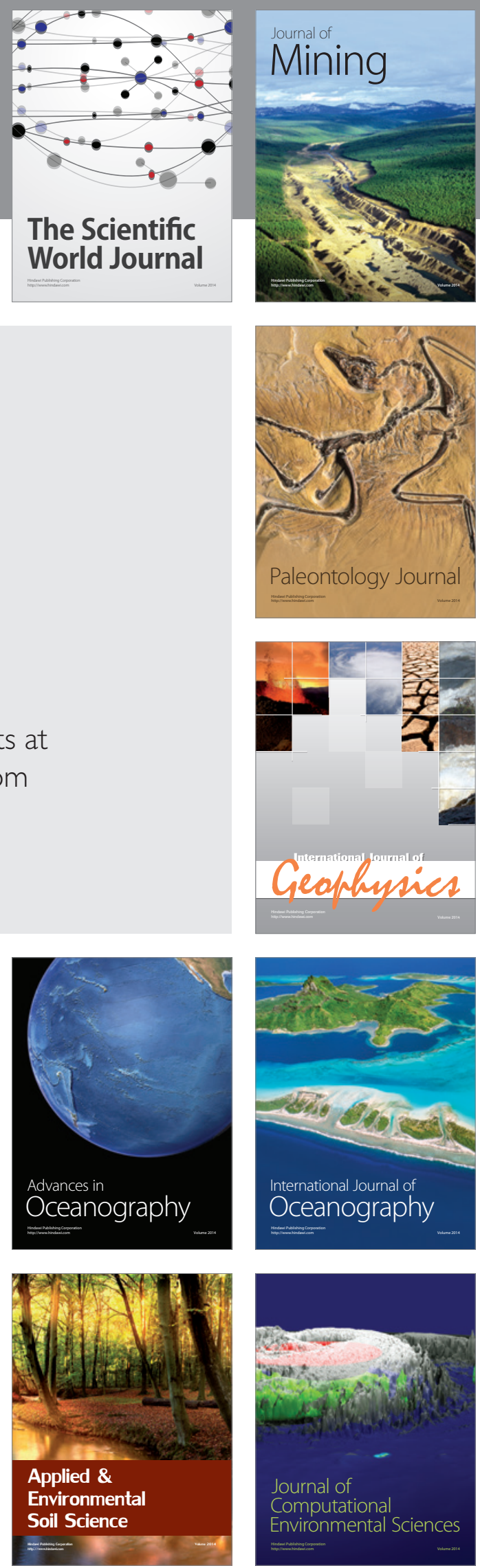